\title{
سياسات إدارة التدفقات المالية الدولية إلى الاقتصادات الصاعدة
}

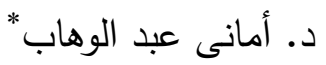

\section{مقدمة}

تتسم تدفقات رؤوس الأموال الدولية إلى الاقتصادات الصاعدة بالتقلب الثديد مقارنة

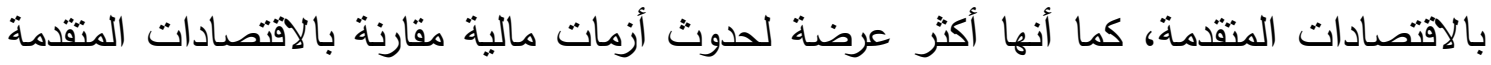
نتيجة الارتداد المفاجيء لتلك التذفقات. فعلى سبيل المثال، شهدت الاقتصادات الناشئة خروجاً كبيراً لرؤوس الأموال وتقلب أعلى في معدل نمو الناتج المحلي الإجمالي مقارنة بالاقتصادات

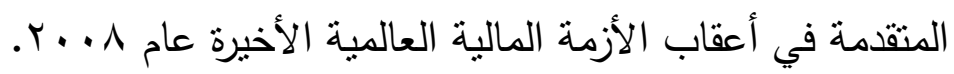

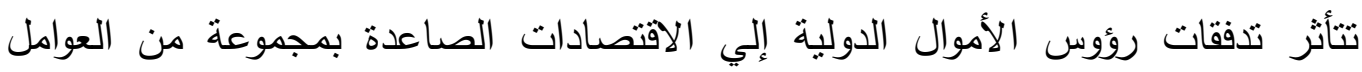

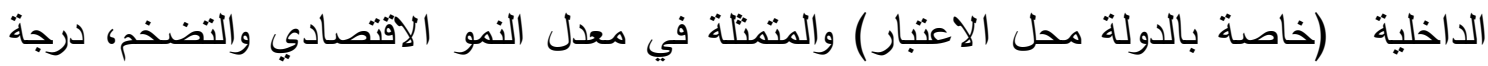
الانفتاح التجاري والمالي، ومستوي نتمية القطاع المالي، ونسبة الكفاءة المؤسسية للدولة، حيث إنه مع وجود بيئة اقتصادية مستقرة ومستوي مرتفع من التتمية المالية تزبد تدفقات رؤوس الأموال

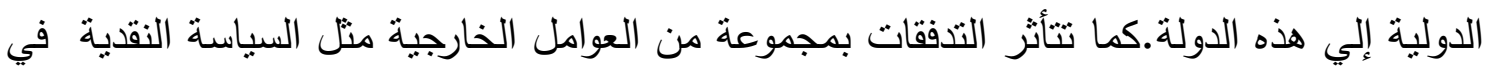

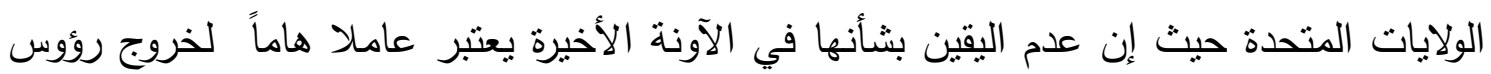

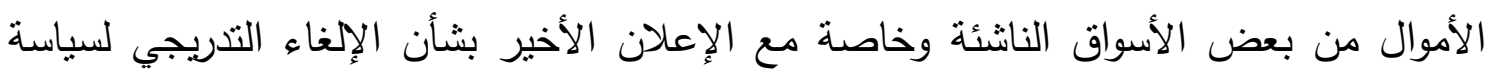
التيسير الكمية.' وكذلك تتأثر التدفقات بتوقعات نمو الاقتصاد العالمي ونمو السيولة الدولية. ونظراً للمخاطر الكبيرة التي تتعرض لها الاقتصادات الصاعدة نتيجة تقلب تدفقات رؤوس الأموال الدولية (الواردة إليها) والمتمثلة في تسخين الاقتصاد مع تدهور الحساب الجاري وحدوث هشاشة مالية Financial fragility من الضروري إيجاد إطار لإدارة تدفقات رؤوس الأموال الدولية وتحديد السياسات الممكنة لمواجهة تلك التقلبات. 
ويتكون البحث من عدد من الأفسام وهى المخاطر المرتبطة بتدفقات رؤوس الأموال

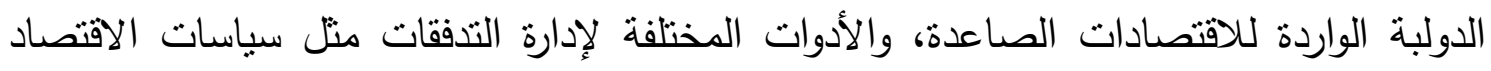

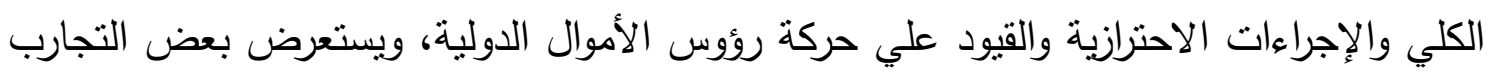

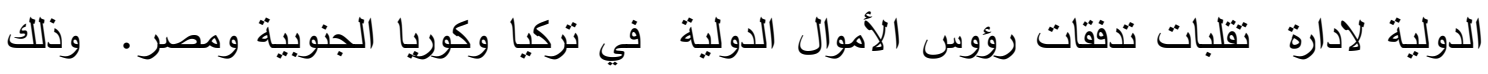

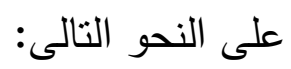
تختلف التدفقات من حيث درجة استقرارها وبالتالي تأثثرها علي احتمال اندلاع الأزمات

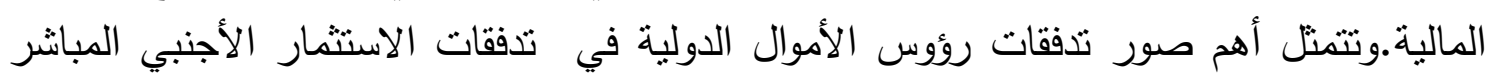
وتدفقات استثمارات الحافظة وتدفقات المديونية.

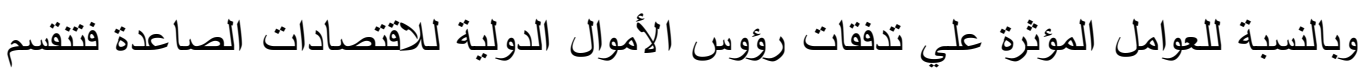

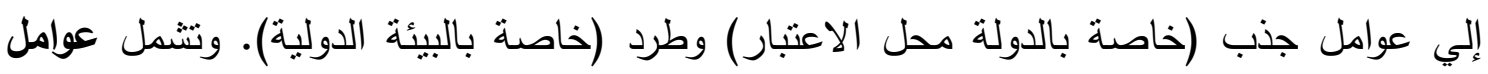

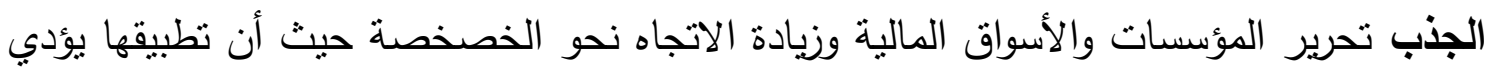

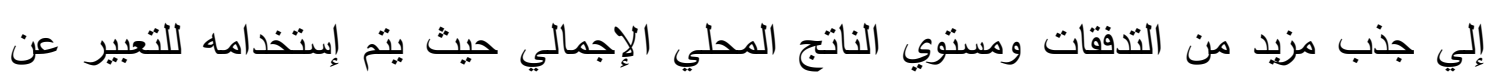

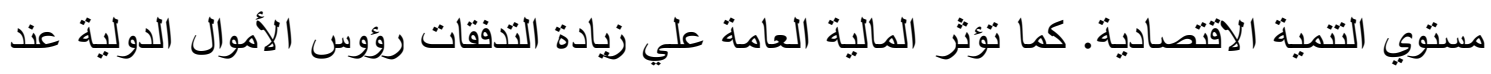

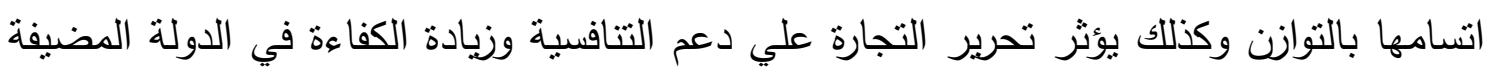

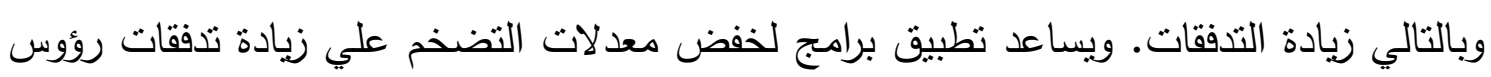

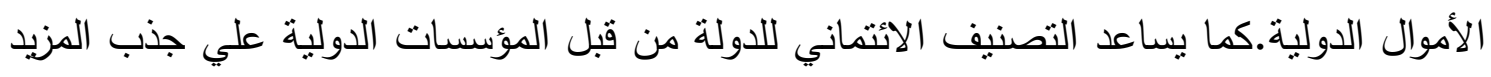

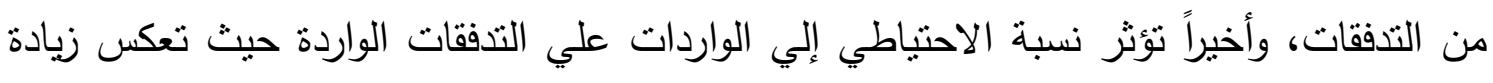

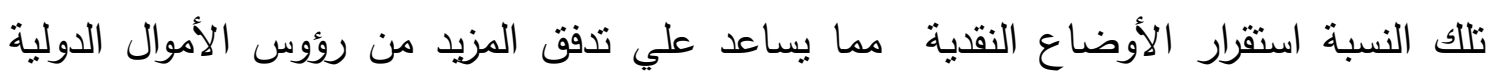
.Beck et al (2000) أما عن عوامل الدفع أو الطرد فنتبير إلي العوامل الخارجية والتي تكون خارج سيطرة

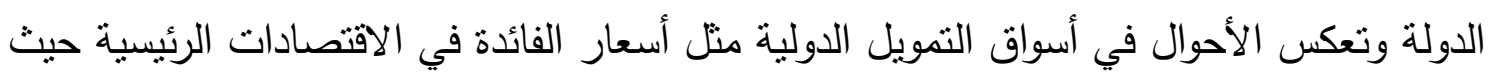


إنه مع انخفاض اسعار الفائدة في الاقتصادات المتقدمة تزيد تدفقات رؤوس الأموال الدولية للاقتصادات الصاعدة. كما تعتبر بعض مؤشرات الاقتصاد الرئيسية في الولايات المتحدة متل دليل

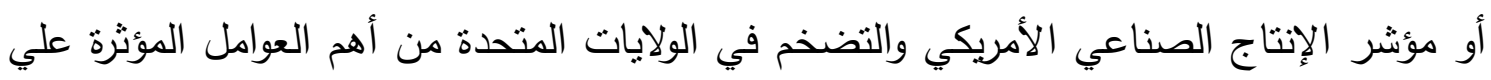

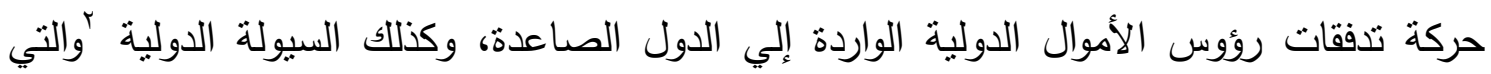

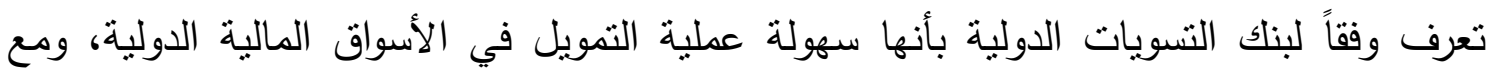

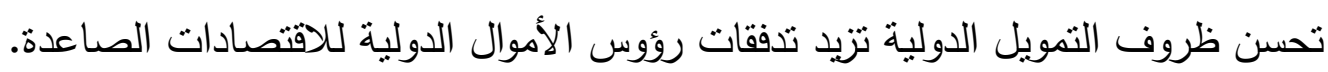

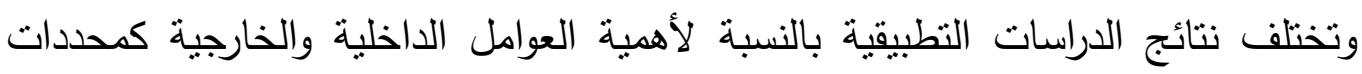

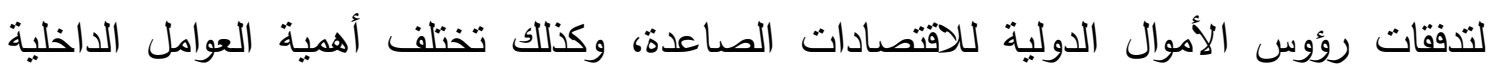

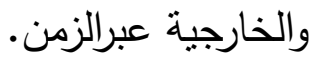

فوفقاً لـ (2011) Fraztzscher اعتبرت العوامل الخارجية من أهم العوامل المحددة

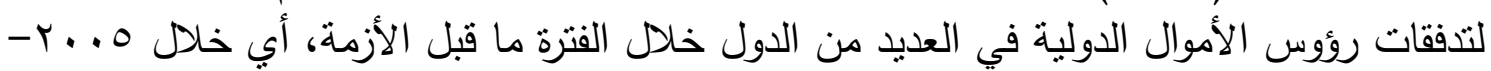

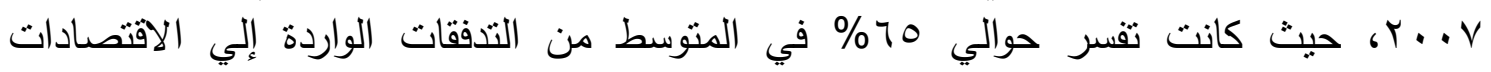

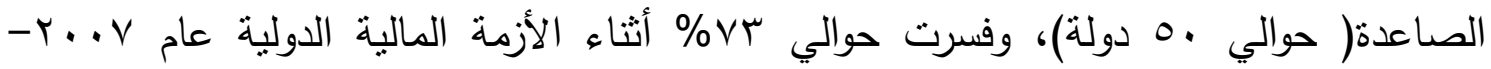

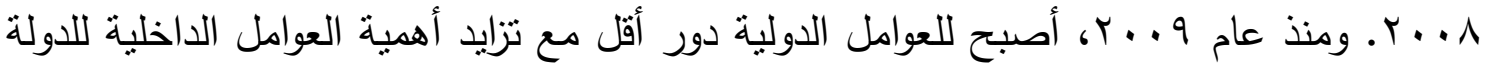

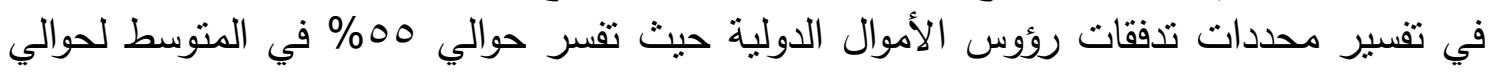

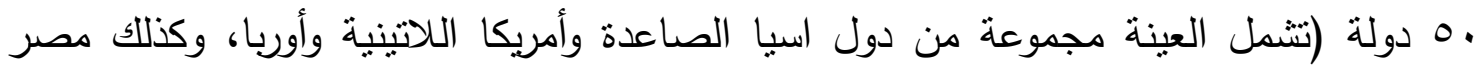

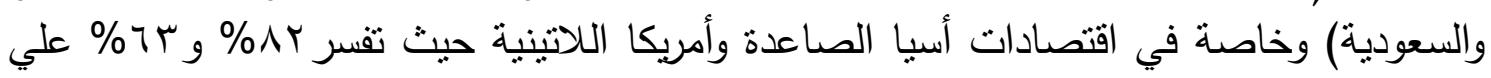

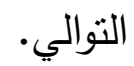

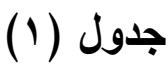

العوامل الخارجية والداخلية في تفسير تدفقات رؤوس الأموال الدولية ( \% التدفقات)

\begin{tabular}{|c|c|c|c|c|c|}
\hline \multicolumn{3}{|c|}{ العوامل الداخلية \% } & \multicolumn{3}{|c|}{ العوامل الخارجية\% } \\
\hline بعد الأزمة & الأزمة & قابل الأزمة & بعد الأزمة & الأزمة & قبل الأزمة \\
\hline
\end{tabular}




\begin{tabular}{|c|c|c|c|c|c|c|}
\hline 00 & TV.r & $r \varepsilon .7$ & $\leqslant 0$ & $V Y . \wedge$ & $70 . \varepsilon$ & جميع الدول \\
\hline 11.9 & 10.1 & $01 . V$ & $1 \wedge .1$ & $\wedge \varepsilon .9$ & $\varepsilon \wedge . \Gamma$ & اقتصادات أسبا الصاعدة \\
\hline 19.8 & 7.1 & $1 T . \varepsilon$ & A.r & $9 r .4$ & 1.. & اقتصادات أوروبا الصاعدة \\
\hline ד. & $0 . . \cdot-$ & $01 . r$ & r..9 & 10. & $\sum \wedge . \wedge$ & أمريكا اللاتينية \\
\hline$\varepsilon 0 . r$ & $\varepsilon . \varepsilon-$ & $9 . \Gamma_{-}$ & $0 \leqslant .1$ & $1 \cdot \varepsilon . \varepsilon$ & 1.9 .5 & أفريقيا والثرق الأوسط \\
\hline 10.1 & VT.1 & 9.1 & $\Lambda \varepsilon . r$ & TT.T & $9 . .1$ & دول أوروبا المتقدمة \\
\hline$\varepsilon 1.4$ & 19.0 & rT.9 & $0 \wedge .1$ & $1 . .0$ & $V 7.1$ & الاقتصادات المتقدمة الأخري \\
\hline
\end{tabular}

http://voxeu.org/article/drivers-global-capital-flows-pushes-or-pulls : المصدر

r - المخاطر المرتبطة بتدفقات رؤوس الأموال الدولية الواردة للاقتصادات الصاعدة:

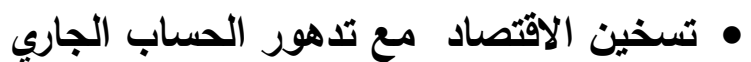
تؤئز تدفقات رؤوس الأموال الدولية الواردة علي زيادة المخاطر علي مستوي الاقتصاد الكلي لأنه مع ذحدوث زيادة كبيرة في التدفقات ترتفع قيمة سعر الصرف (خاصة في الدول التي تتبع سعر صرف مرن) وهو ما يؤدي بدوره إلي التقليل من القدرة التتافسية و إضعاف الحساب الجاري وكذلك بطء النمو الاقتصادي والإضرار بعملية التتمية الاقتصادية. وقد تؤثز فترات التدفقات الكبيرة علي ولي إني زيادة عرض النقود مقارنة بالطلب علي النقود وخاصة في الدول التي تتبع سعر صرف ثابت (إذا

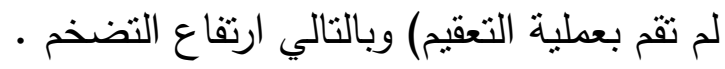

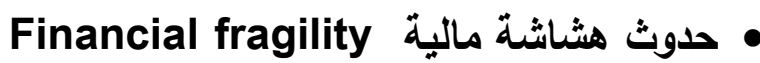
يقصد بالهثاشة المالية هنا تفاقم المخاطر المالية للنظم المالية المحلية عندما تقوم بعملية الوساطه لرأس المال المحلي والأجنبي •وترتبط بتدفقات رؤوس الأموال ثلاثثة مخاطر ألا وهي: مخاطر بهر الائتمان، مخاطر السوق (على وجه الخصوص مخاطر سعر الصرف)، ومخاطر السيولة.

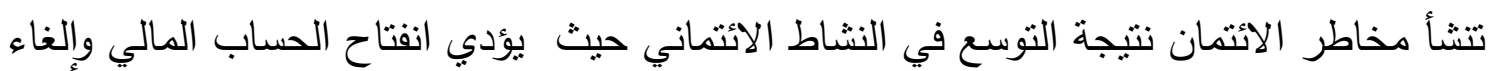
القواعد التنظيمية المالية أو تخفيضها إلى الإفراط في اقتراض الأموال الأجنبية وزيادة احتمالية التخلف عن السداد دع عدم وجود هيئات مالية رقابية وإشرافية كفء حيث يتم توجيه رؤوس الإن إنه

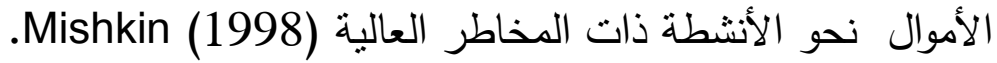


أيضاً تعتبر مخاطر سعر الصرف من أهم مخاطر السوق وتتعرض البنوك لتلاك المخاطر إذا لم

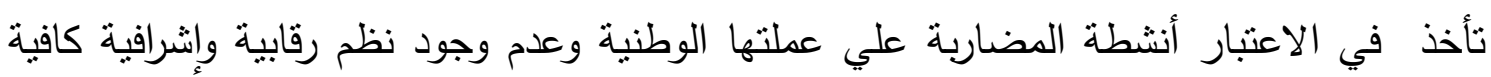

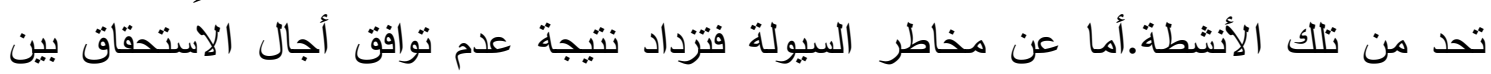

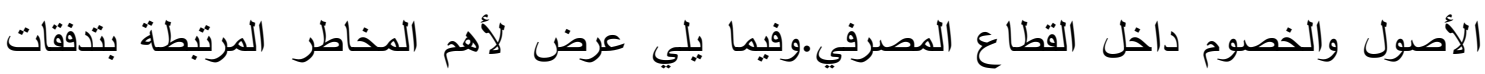
رؤوس الأموال الدولية التي تؤدي إلي زيادة الهشاثشة المالية وسبل إدارتها.

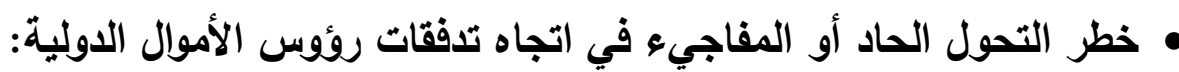

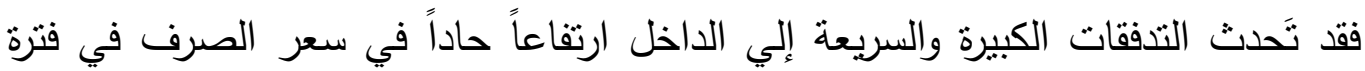

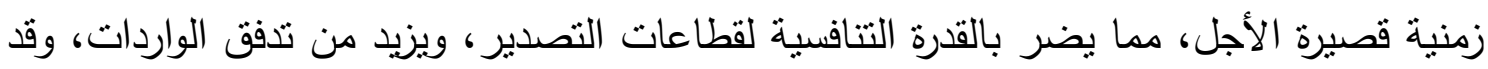

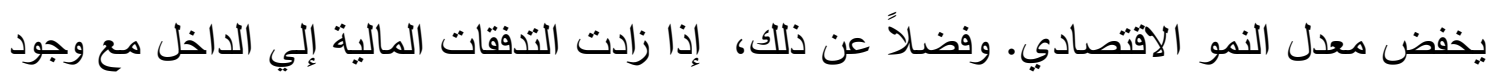

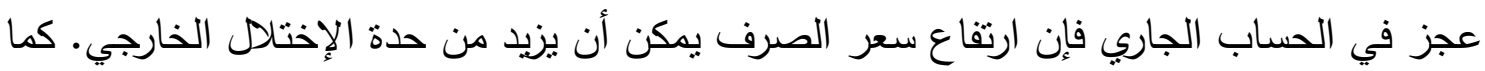
أنه من منظور تحقيق الاستقرار الاقتصادي الكلي، قد يؤدي نراكم الاحتياطيات الأجنبية - اللازمة الإنة

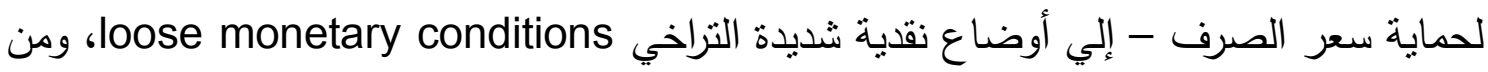

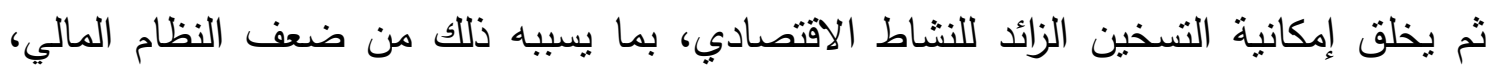
وتضطر السلطات النقدية إلي التعقيم (النشار ، 9 . . ب). تقييد حرية السياسة النقدية في تنفيذ بعض الأهداف الفئ

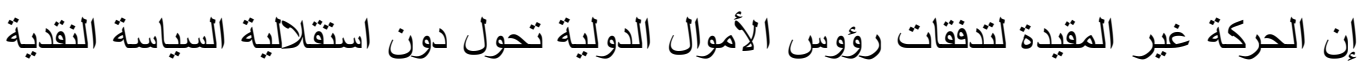

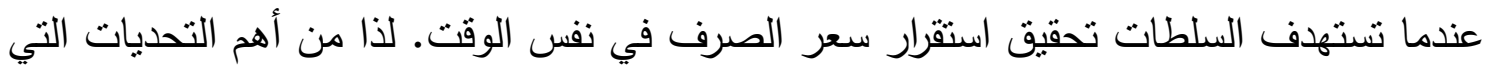

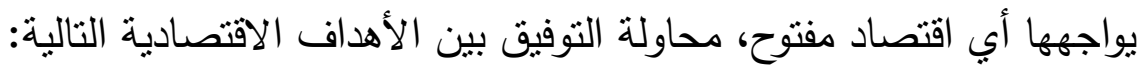

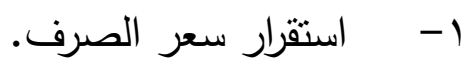

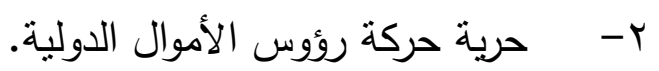

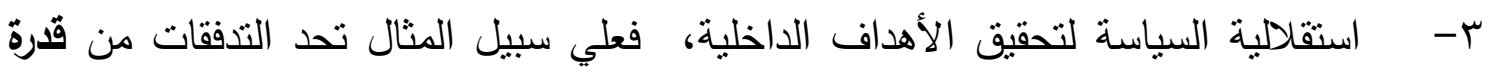

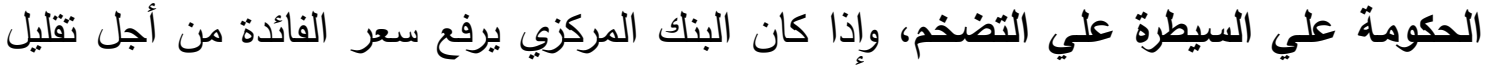

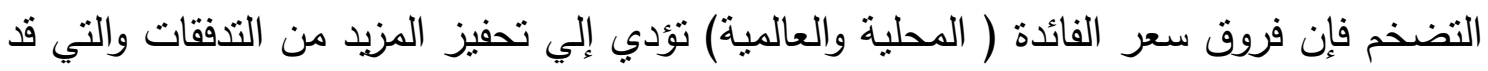
it 
تبطل أثر السياسة النقدية من خلال خلق ضغوط لخفض سعر الفائدة.وقد نجح العديد من

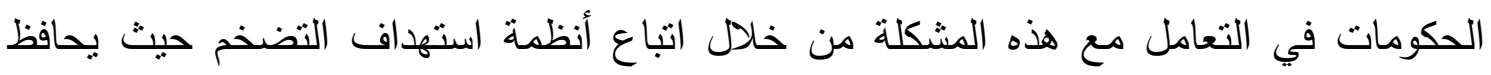

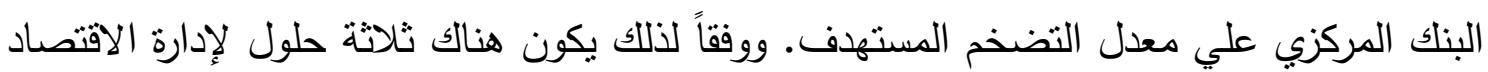
بشكل سليم في ظل الاقتصاد المفتوح:

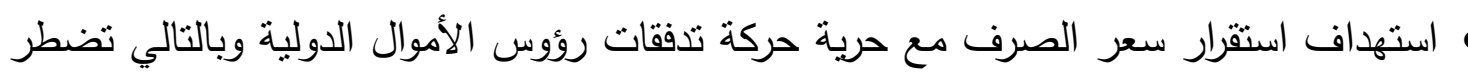
السلطات النقدية إلي التخلي عن استقلالية السياسة النقدية وتكون عاجزه عن تحفئ تحقيق الأهداف

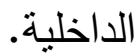
• محاولة تحقيق استقلالية السياسة النقدية مع تحرير حركة رؤوس الأموال الدولية وبالتالي حدوث تقلبات شديدة في سعر الصرف. استهداف استقرار سعر الصرف مع الحفاظ علي استقلالية السياسة النقدية وبالتالي ضرورة اللجوء إلي إدارة حركة تدفقات رؤوس الأموال الدولية.

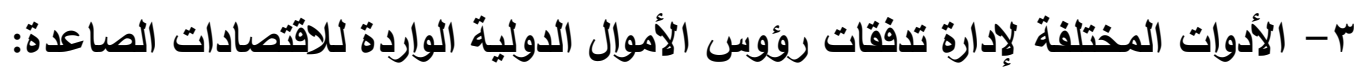

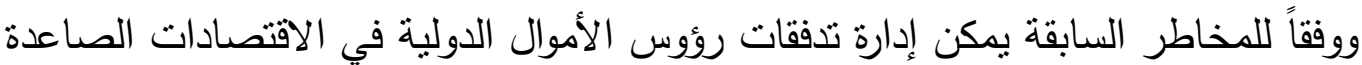

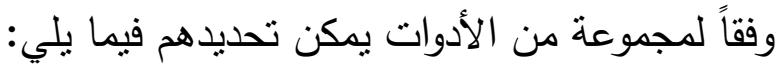

$$
\begin{aligned}
& \text { (1) (1) إجراءات احترازية. }
\end{aligned}
$$

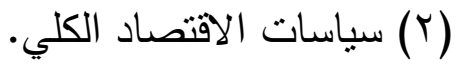

$$
\begin{aligned}
& \text { (r) قيود علي حركة رؤوس الأموال الدولية. }
\end{aligned}
$$

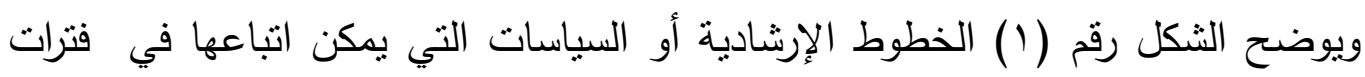

زيادة تدفقات رؤوس الأموال الدولية الواردة والتوقيت الإنظاديه الذي يمكن فيه استخدام الضوابط لإدارة المخاطر الناجمة عن تلك التدفقات، ويتكون الثنكل من فرعين أساسين: إدارة المخاطر المرتبطة

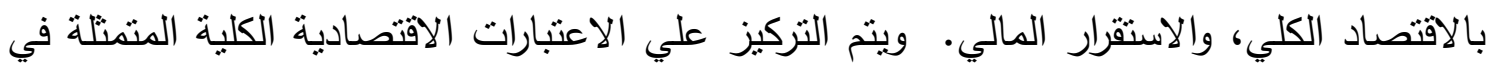


تأثير إجمالي التدفقات علي ارتفاع أسعار الصرف، وكذلك القضايا المتعلقة بتشخين الاقتصاد والتضخم. إما بالنسبة لاعتبارات الاستقرار المالي فتهنم بتغطية المخاطر الناجمة عن نمو الائنمان، وزيادة أسعار الأصول المتتوعة ومخاطر هيكل الالنزامات الخارجية للبنوك والمؤسسات الغير مالية (مثال الاعتماد علي تمويل قصير المدي لتمويل أصول طويلة المدي). ويمكن أن تتواجد هذه المخاطر (مخاطر الاستقرار المالي) في القطاعات المالية والغير مالية علي حد سواء. وتعتبر السياسـات الاقتصادية الكلية والاحترازيـة من أهم السياسـات لمواجهة مخاطر عدم

الاستقرار المـالي والاقتصـادي علي التوالي، ويتم استخدامها معـاً لمواجهة الصـمات الاقتصـادية القويـة، سـواء كانـت هذه الصـدمات مرتبطـة بتدفقات رؤوس الأمسوال الدوليـة أم لا.وتحتـاج تلك السياسات إلي التعديل أو التكيف وفقاً لتدفقات رؤوس الأموال الدولية الكبيرة، وبالتالي زيادة القدرة علي إدارة مخاطر الاقتصاد الكلي والاستقرار المالي. وتعتبر سياسـات الاقتصاد الكلي والإجراءات الاحترازية المالية خط الدفاع الأول ضد مخاطر الاستقرار المالي والاقتصادي الناجمة عن طفرات

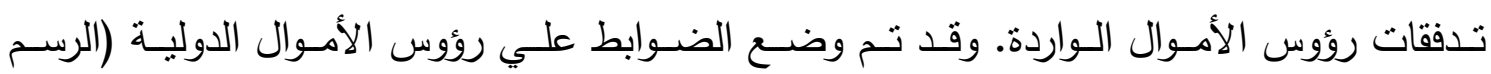
التوضيحي بالأسفل) لكي يتم توضيح أنه بغض النظر عن الفرق في طبيعة واهتمامات الاقتصاد الكلي والاستقرار المالي، يجب أن تأتي الضوابط بعد الوسائل الأساسية التي تستخدم في مواجهة موجات تدفقات رؤوس الأموال الدولية، وعلي السلطات النقدية أن تستخدم أولا سياسات الاقتصاد الكلي وتسعي لتقوية سعر الصرف، بالإضافة إلي تقوية وسائل الإجراءات الاحترازية غير التمييزية قبل اللجوء إلي فرض ضوابط علي رؤوس الأموال الدولية.

شكل (1)

الخطوط الإرشادية أو السياسات لإدارة موجات تدفقات رؤوس الأموال الدولية 


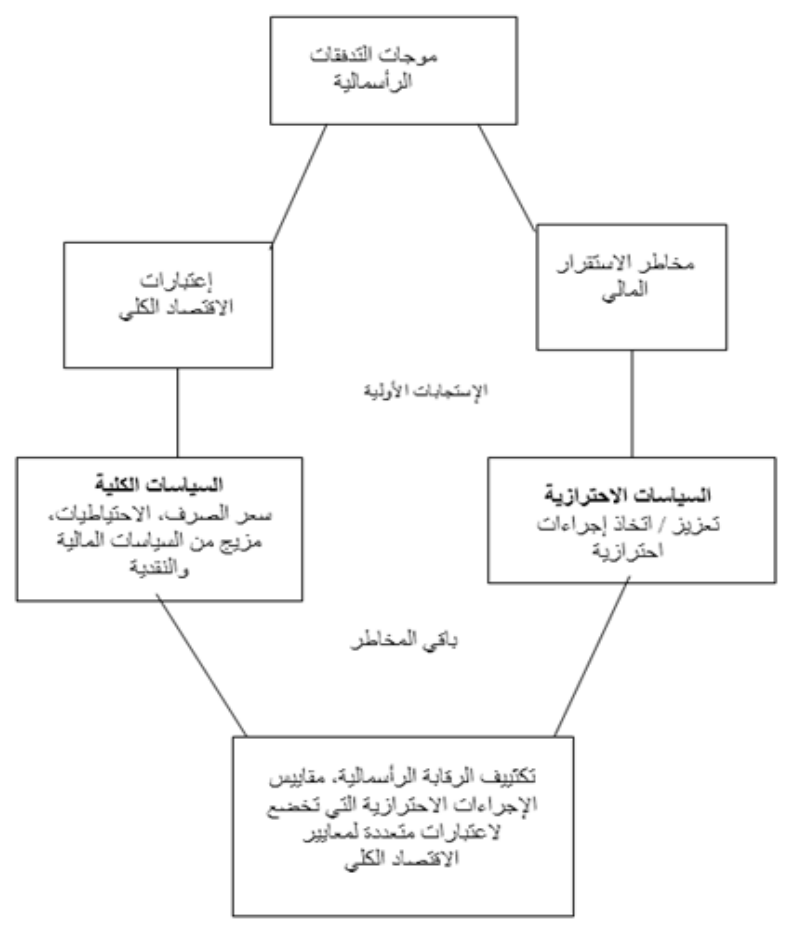

Source: Ostry et al, 2010, Managing Capital Inflows: What Tools to Use?, IMF Discussion Note, SDN/11/06.

1- السياسات الاقتصادية الكلية

تعتمد الاستجابة الملائمة للخطر المرتبط بتدفقات رؤوس الاموال على هيكل التدفقات، وكفاءة مختلف السياسات القائمة وخصائص السوق المالي (khan and Reinhart , 1995). وتتمنل السياسة الاقتصادية الكلية لإدارة تدفقات رؤوس الاموال وخاصة الاموال الساخنة في الأتي

(Ostry et al., 2010) 


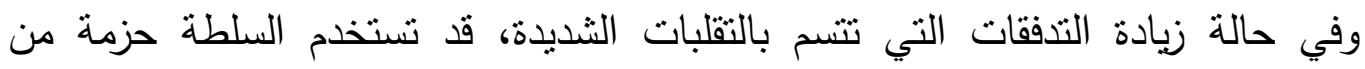

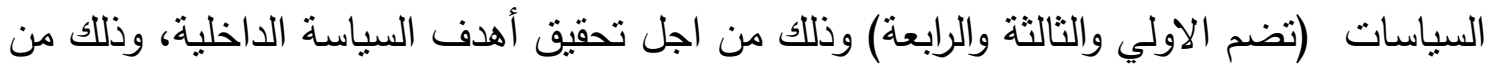

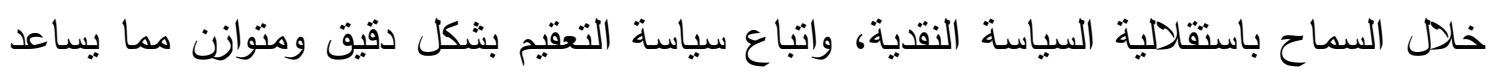

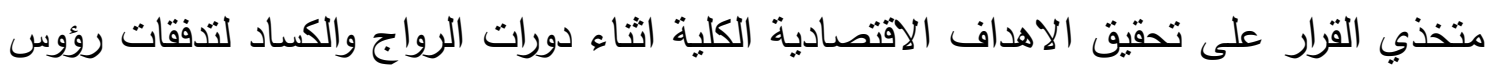

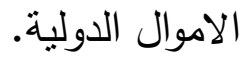

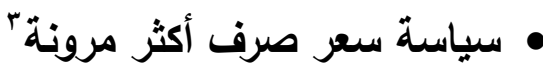

من الممكن أن تكون سياسة أو استجابة لتقلبات تدفقات رؤوس الاموال الدولية ولا يعني

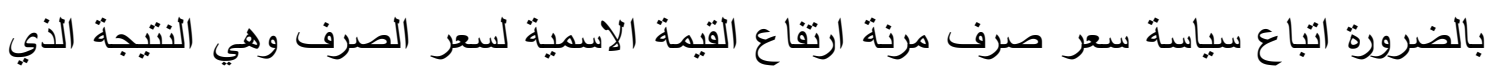
يحاول متخذي القرار تفاديها. يخفف نظام سعر الصرف المعوم من اثر رؤوس الاموال المضاربة ويمنع التدققات المتزايدة من خلال خفض توقعات حدوث زيادة فى سعر الصرف، كما أنه يساعد فى امتصاص

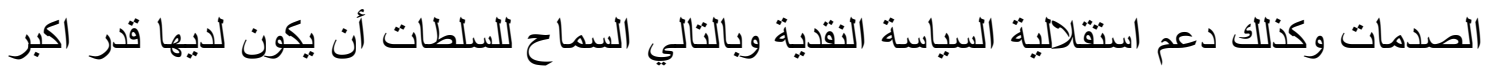
من الحرية لإدارة التقلبات فى المؤشرات النقدية الكلية الناجمة عن تدققات رؤوس الأموال.

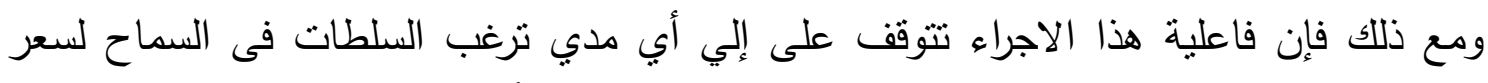

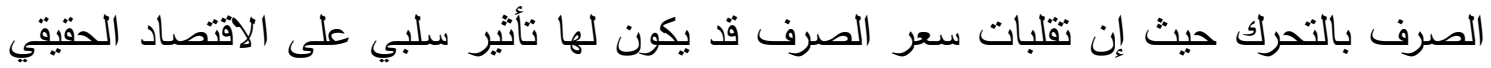

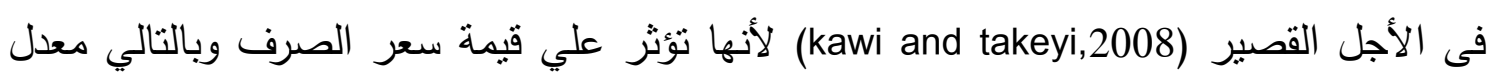
التبادل التجاري والقطاع الخارجي.

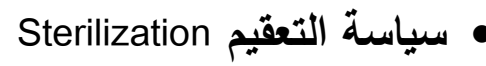


هي عملية التذخل من قبل البنك المركزي عن طريق عمليات السوق المفتوحة أو غيرها

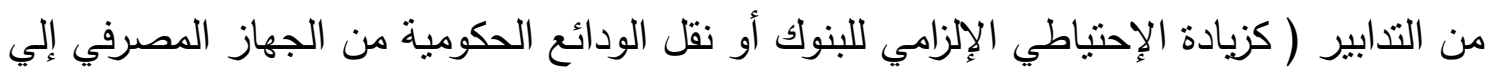

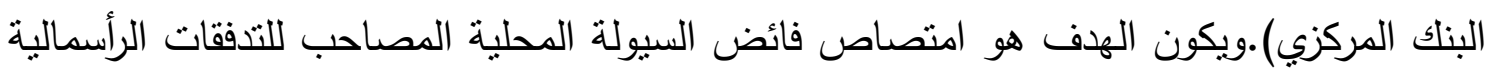

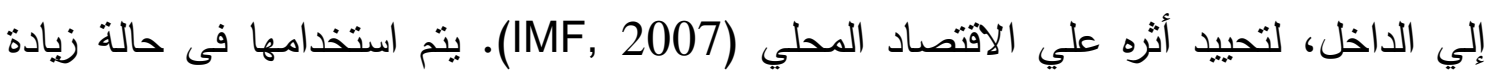

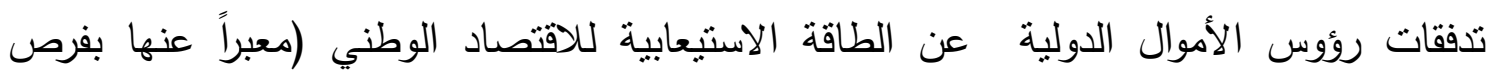

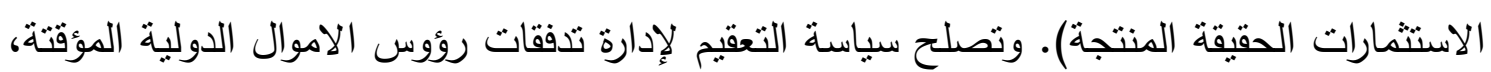

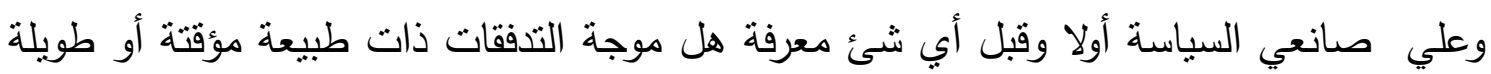

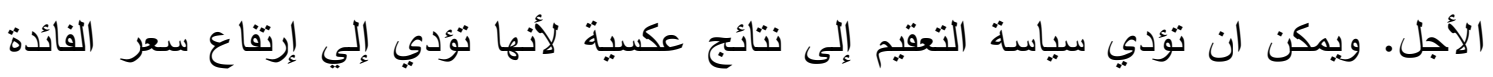

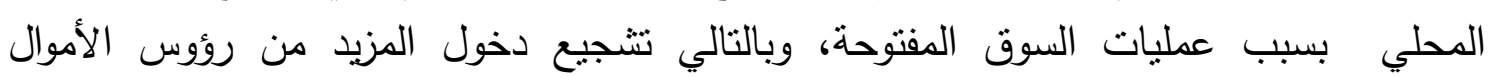

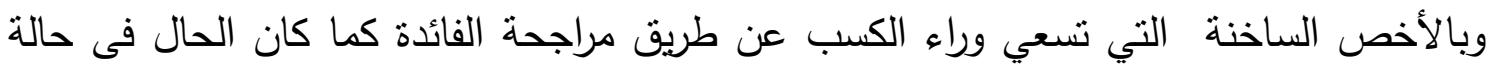
إندونيسا وماليزيا خلال النسعينيات.

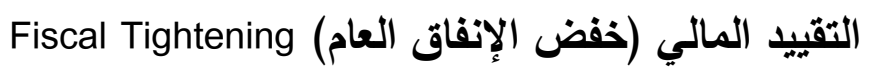

قد تقوم بعض الدول بخفض الإنفاق العام من أجل التخفيف من الضغوط التفان التضخمية

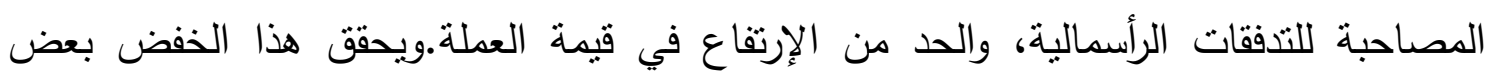

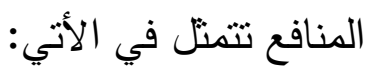
ه خض أسعار الفائدة عن طريق إضعاف الطلب الكلي في فترات التدفقات الواردة المرتفعة وبالتالي إحباط دخول المزيد من التدفقات.

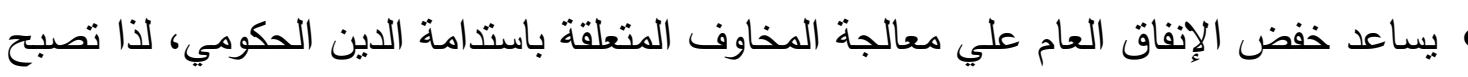

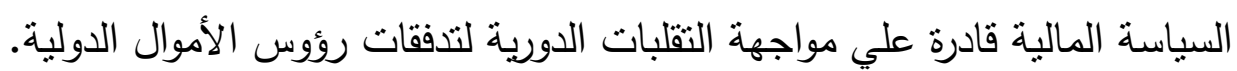
• يشجع خفض الانفاق العام علي جذب واستقرار التذفقات طويلة الاجل. 
Kawai and Takayi , ) ولكن لهذه السياسة المالية ثلاث نقاط ضعف فى مواجهة التذفقات $(2008$ 1- - تعنبر السياسة المالية أقل مرونة حيث إنها تحتاج قرار سياسي أو برلماني كما يكون هناك تأخر فى التنفيذ. ץ- قد تُؤدي إلى إعطاء إثنارة بانه بتم اتباع سياسات اقتصادية كلية كفء وبالتالي دخول مزبد

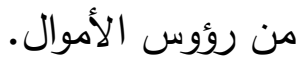
r- محدودية القدرة علي تطبيق سياسة التشديد المالي وخاصة فى المجتمعات الديمقراطية. ونتيجة لهذا يعتبر أثز نلك السياسة على إدارة تقلبات تدفقات رؤوس الأموال الدولية محدود.

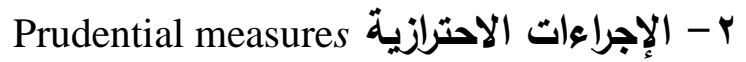

تهدف القواعد الاحترازية إلي تعزيز قدرة القطاع المالي علي التصدي للخطر المتزايد وتتفذ هذه القواعد عادة على مستوى المؤسسات الفردية. وللغرض التحليلي، من المفيد تقسيم هذه الإجراءات إلى "مخاطر النقد الأجنبي" (الإجراءات التي تعتمد على فئة المعاملات عسب العملة) والإجراءات الاحترازبة الأخرى (2010 ). Ostry et al. > الإجراءات الاحترازية لمواجهة مخاطر النقد الأجنبي: تكون وفقاً للعملة، وليس وفقاً لأطراف المعاملة. وتطبق هذه التدابير على المؤسسات المحلية المالية، للبنوك في المقام الأول. وتشمل وضع قيود على استثارات البنوك (الأصول بالنقد الأجنبي) وقيود علي إقراض البنوك بالعملة الأجنبية، وكذللك فرض نسب مختلفة للإحتياطي النقدي وفقاً للإلنزامات بالعملة المحلية والعملة الأجنبية. > الإجراءات الاحترازية الأخرى: تشتهدف تقليل المخاطر المنتظمة تدريجياً، على سبيل المثال، وضع قيود على نمو الائتمان المحلي ومنع مخاطر نركز القروض. ب-ضوابط تدفقات رؤوس الأموال الدولية Capital controls تعرف القيود التي تقرض علي انتقالات رؤوس الأموال الدولية علي أنها التدابير أو الإجراءات الاقتصادية التي تؤثز علي سلوك الفاعلين الاقتصاديين للحد من انتقالات رؤوس الأسوال 
الأموال الدولية.وقد تتشمل هذه التدابير وضع القيود (أومنع) بعض (أو كل) أنواع المعاملات

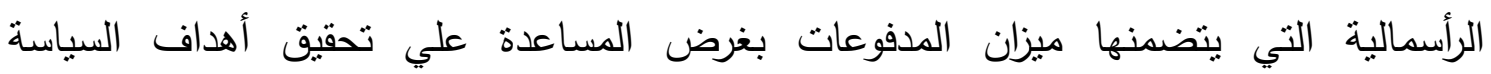

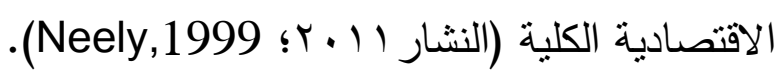
تقرض الضوابط على رؤوس الاموال لمواجهة سلوك القطيع للمستثمرين و دورات الرواج

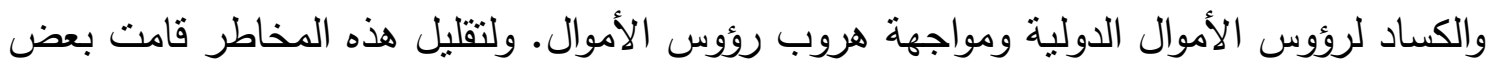

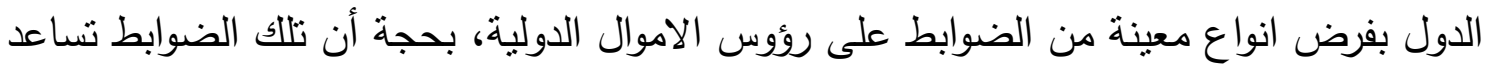

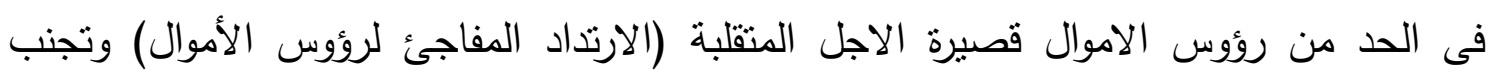

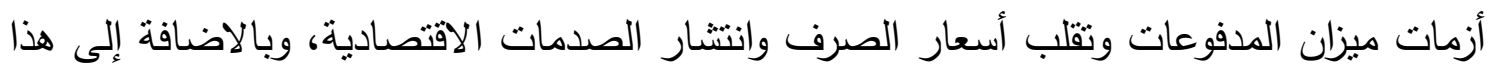
فإن هذه الأداة توفر استقلالية لسياسة سعر الفائدة.

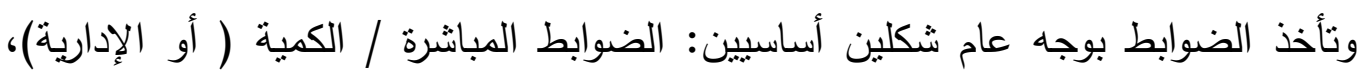

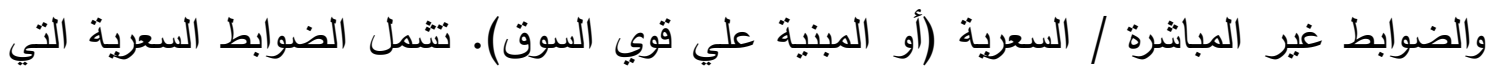

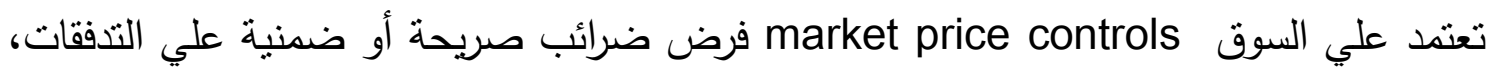
وتحديد أسعار صرف مختلفة للمعاملات الرأسمالية. أما بالنسبة للضوابط الإدارية التي تعتمد علي

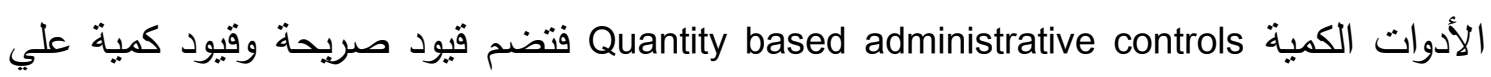
حجم المعاملات مثل حالات الحظر المبانر أو وضع موافقات رسمية لتحويل التمويل خارج الدولة

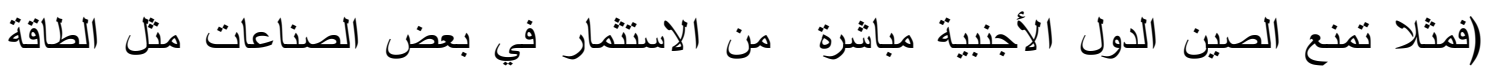

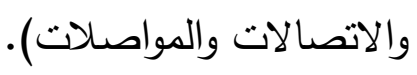

إن الأثر الواضح (وإن لم يكن بالضرورة الأكثر أهمية) للضوابط علي حركة رؤوس الأموال يتمثل

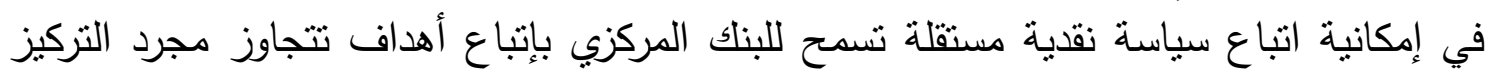

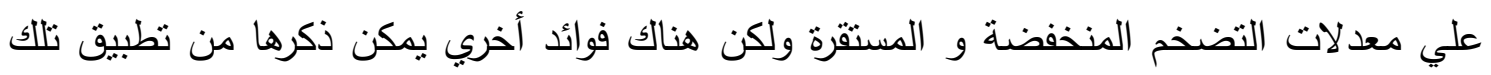

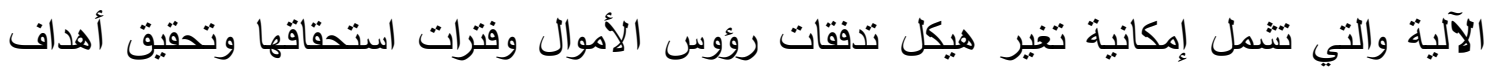


وطنية أوسع نطاقاً من خلال السماح للبلدان أن تكون أكثر انتقائية فيما يتعلق بنوع الاستثمار الذي تحتاجه الدولة والقطاعات المستهدف تطويرها. وهناك جدل كبير حول تأثنر إختيار نوع معين من الضوابط (السابق ذكرها) علي معنوية المستثرين، فوفقاً لـ Stiglitz تعتبر (2006) الضوابط السعرية صديقة للسوق، فهي مرنة وأقل عرضة للتلاعب السياسي، بينما تعنبر القيود الكمية أقل شعبية داخل المجتمع المالي الدولي ولكنها أحياناً تقلل المخاطر بشكل أكثر فاعلية مقارنة بالتذخلات السعرية. وفي الواقع فإن المنهجين يتمتعان بمزايا معينة، كما أن معظم البلدان استخدمت مزيجاً من الإثثين. فتعتبر الضوابط السعرية مفيدة للغاية لأنها تقدم إجراءات وقائية prudential concerns في الاقتصادات النامية التي تقتقر إلي مؤسسات تتظيمية مالية مناسبة، كما أنها أكثر فاعلية في تغير هيكل تدفقات رؤوس الأموال الدولية، إلا أنه يمكن التحايل علي تلك الضوابط بسهولة حتي عندما تطبق علي نحو ملائُ. وقد أشار Ostry et al.2010) إلي أنه حتي لو قام المستثرون بوضع استراتيجيات للتحايل علي تلك الضوابط، تعنبر تكلفة هذه العملية أعلي من العائد المتوقع منها. وأكد( Stigltz et al, إلي أن التخخلات يجب ألا تكون متلي حتي تتسم بالفاعلية، فما يهم هو استمرار قدرة تلك الضوابط علي تحقيق استقرار التدفقات. وبالنسبة للضوابط الإدارية فيمكن استخدامها ولكنها غير متتاغمة مع السوق وقد تؤدي إلي تراجع الاستثمار حتي بعد إزالة القيود،

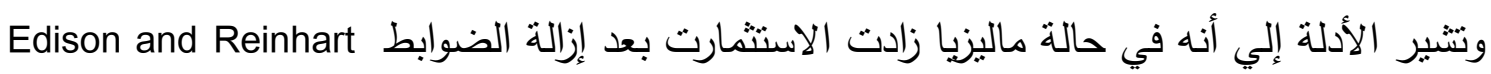

ع - التجارب الدولية لإدارة تدفقات رؤوس الأموال الاولية مع إثارة خاصة لمصر ع - 1 إدارة تدفقات رؤوس الأموال في كوريا الجنويية

شهدت كوريا الجنوبية حجم كبير من تدفقات رؤوس الأموال الدولية حيث زاد إجمالي

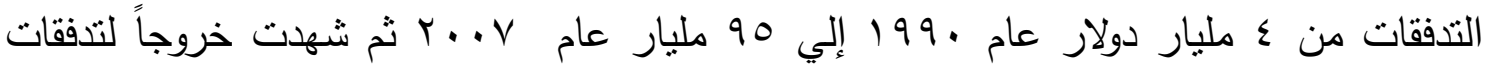
vi 
رؤوس الأموال عام ^ . . ץ ثم اخذت اتجاهاً تصاعدياً مرة أخري لتصل إلي ج ـ ا مليار دولار عام

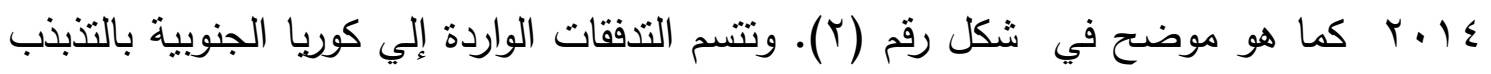
بدرجة كبيرة وخاصة أثتاء الأزمات المالية، حيث شهدت انخفاض جميع التدفات أثناء الأزمة المالية العالمية وبالأخص استثمارات الحافظة والاستثمارات الأخري، بينما شهد الاستثمار الأجنبي المباشر قدراً من المقاومة أثتاء الأزمة المالية العالمية. ويوضح هيكل التدفقات الداخلة استحواذ القروض المصرفية (وخاصة قصيرة الأجل) واستثمارات الحافظة علي نسبة كبيرة من تدفقات رؤوس الأموال، أكثر من نصف التدفقات الخاصة الي الاقتصاد الكوري، ويتجه نصيب الاستثمار الأجنبي المباشر إلي الانخفاض. الاضونان.

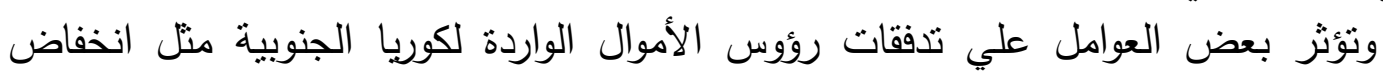

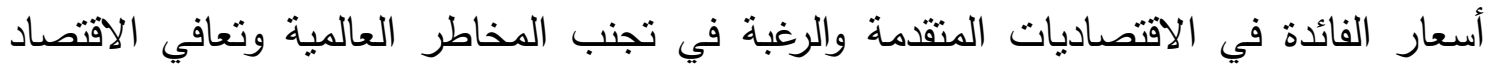

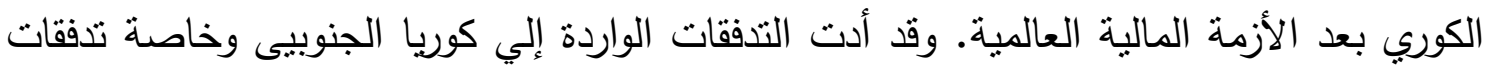

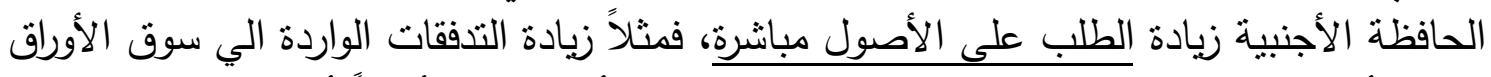

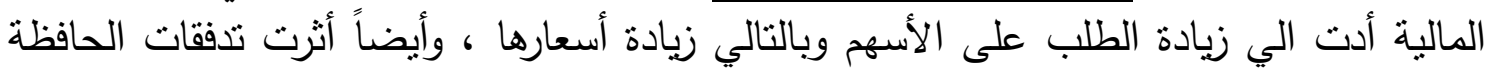

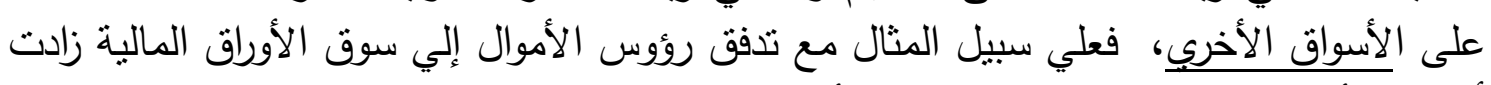

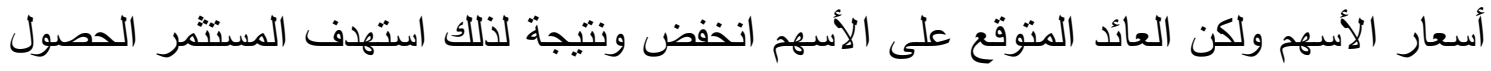

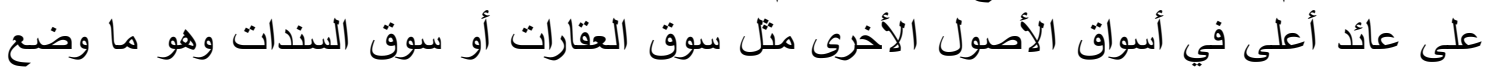

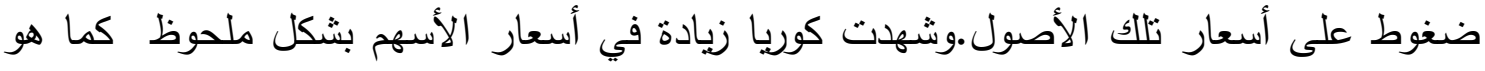
موضتح في الثكل رقم (ع) نتيجة زيادة الاستثمار الأجنبي داخل سوق الأوراق المالية المحلية.

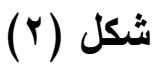

تطور تدفقات رؤوس الأموال الواردة الي كوريا خلال القترة • 99 1 - ـ 1 ـ . . 


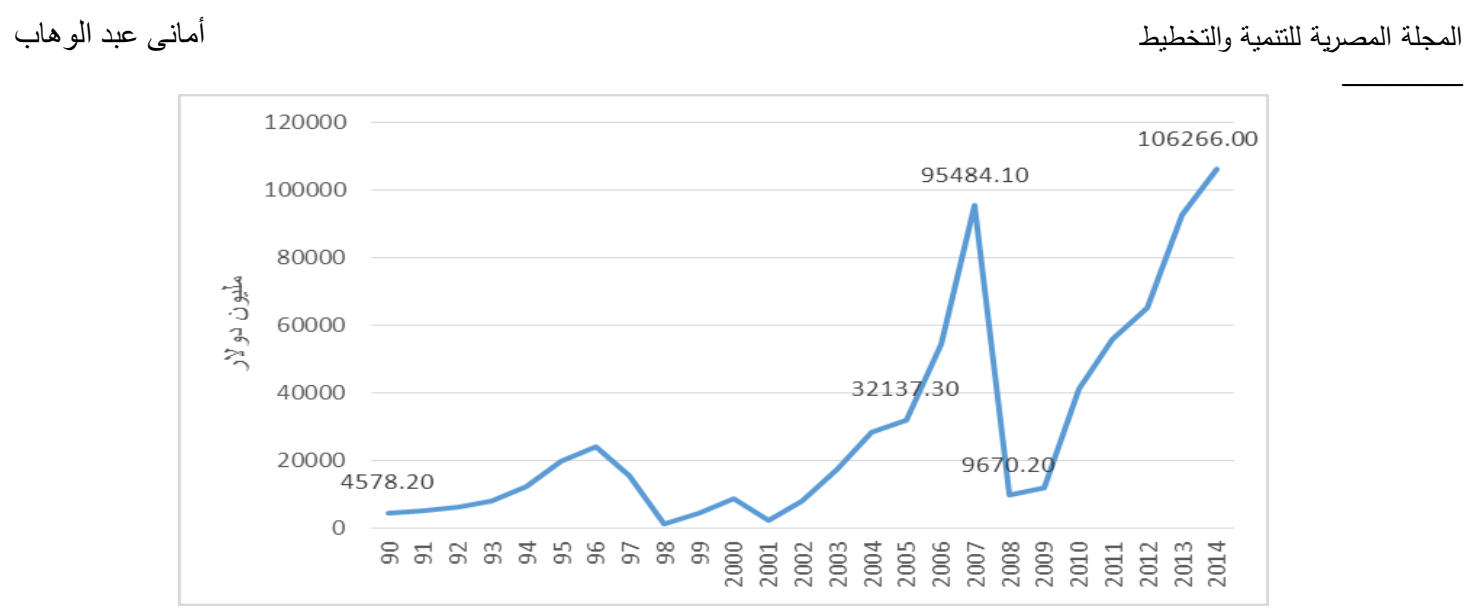

شكل (r)

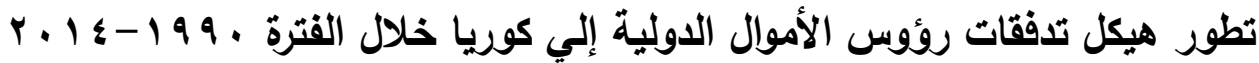

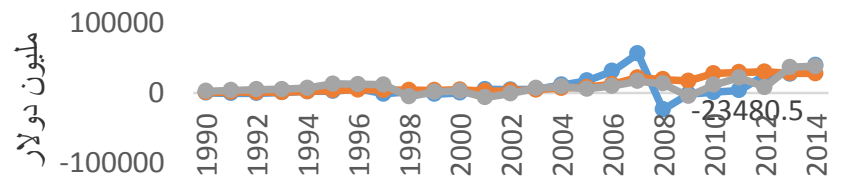

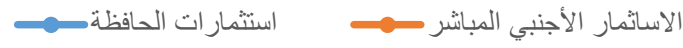

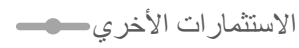

international financial statistics, online database :

http://data.imf.org/?sk=388DFA60-1D26-4ADE-B505-A05A558D9A42

شكل (ع)

تطور أسعار الأسهم في سوق الأورلق المالية الكورية

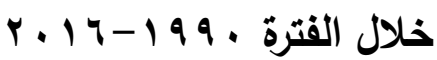

Vr 


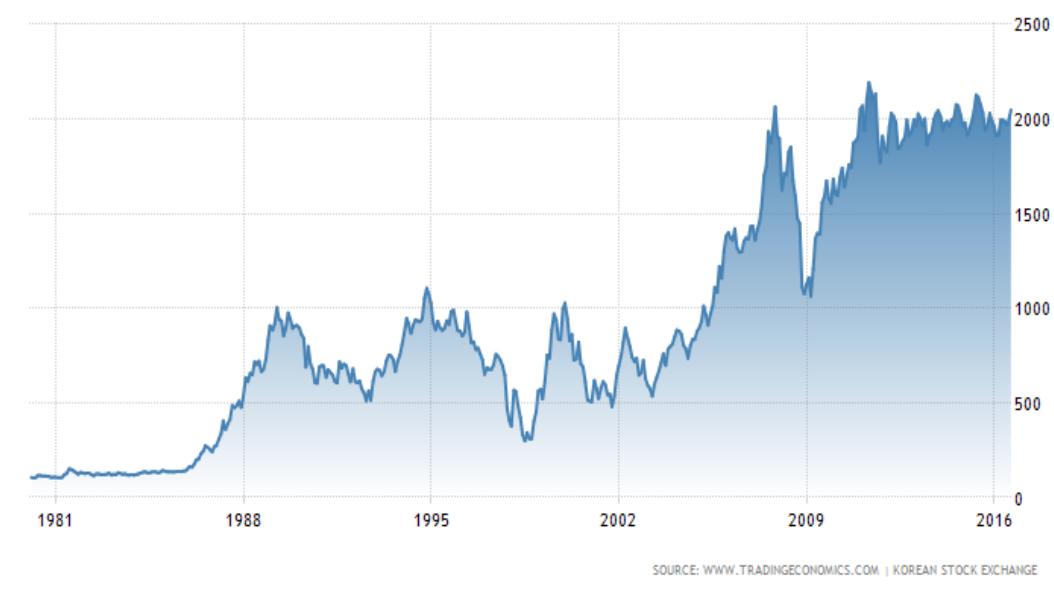

http://www.bok.or.kr/eng/engMain.action

المصدر : الموقع الرسمي للبنك المركزي الكوري

وقد تم إتباع مجموعة من السياسات لإدارة تدفقات رؤوس الأموال الدولية في كوريا الجنوبية يمكن

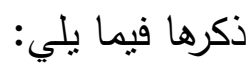
- تم تحرير الحساب الرأسمالي في أوائل التسعينات، ففي عام ب999 199 تم السماح للمستثر

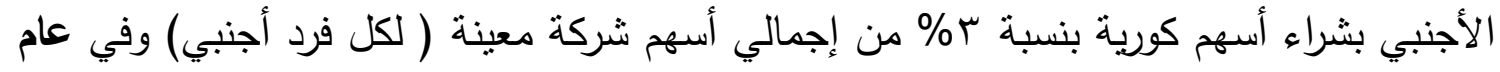

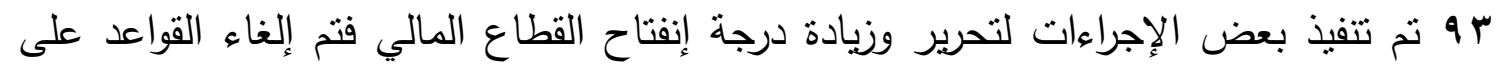

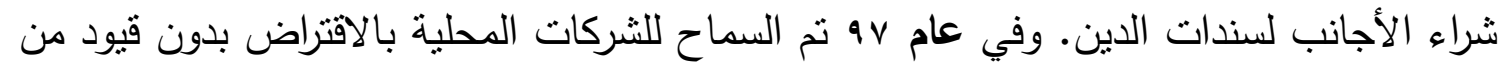

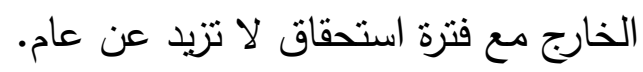

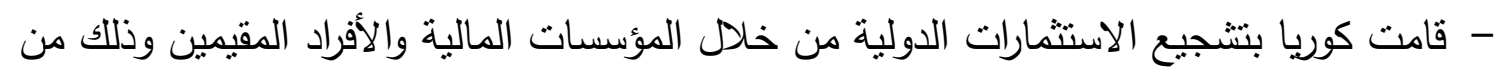

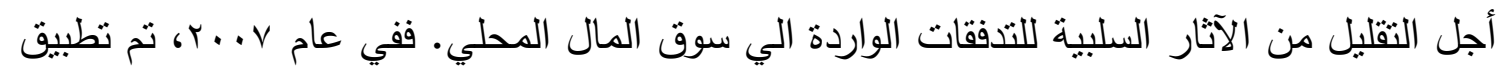

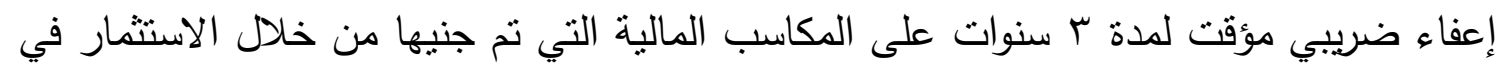
الأسهم دولياً من قبل المستثمرين المحليين والثركات الاستثمارية. 
- نظراً لأن القروض الخارجية قصيرة الأجل تمثل تهديداً بالنسبة للقطاع المصرفي الكوري، تم تتفيذ مجموعة من التدابير الثاملة، ففي نوفمبر 9. . ب، تم تحديد مستويات أعلي للسيولة بالعملة الأجنبية للحد من مشكلة عدم تطابق أجال استحقاق الأصول والخصوم بالعملات الأجنبية لدى في

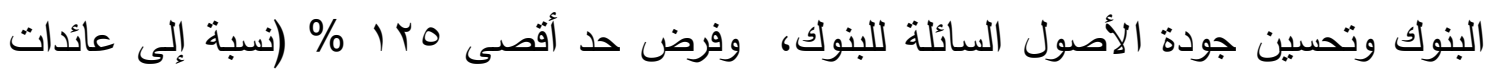
التصدير) على عقود الصرف الأجنبي الآجلة بين البنوك والمصدرين. وفرض قيود علي التمويل

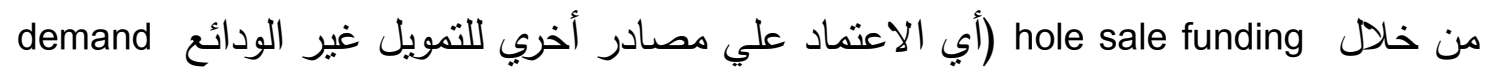
deposit علي نسبة . . 1 \% للقروض إلي الودائع وبالتالي ستكون البنوك قادرة على تقديم قروضها للأسر أو الثركات من خلال الودائع الأساسية للبنك demand deposit. وأخيرا، تم تحديد معدل كفاية رأس المال وتطبيقه بشكل أكثر صرامة لاستيعاب الخسائر المحتملة عند القيام بالأنشطة المصرفية.

- تم فرض ضريبة احتراز الاستقرار الكلي Macroprudential Stability Levy علي الخصوم بالعملة الأجنبية والتي لا تدخل ضمن الودائع (non-deposit FX liabilities) حيث تكون نسبة الضريبة كبيرة مع قصر فترة الاستحقاق حيث تصل إلي .r\% بإذا كانت فترة الاستحقاق أقل من

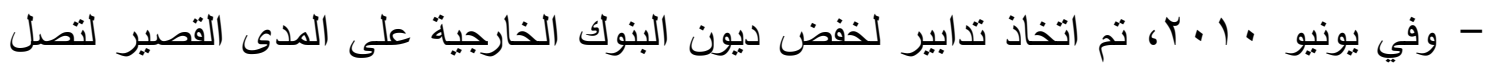
إلي صفر zeroing bank short-term external debt فقرضت السلطات ضوابط علي نسبة المشتقات المالية الأجنبية إلي رأس مالها، للحد من الديون الخارجية قصيرة الأجل التي نتجت عن تقديم البنوك عقودا آجلة للشركات. وكان الهدف من هذا الإجراء هو تقليل البنوك الخارجية والخروج المفاجيء لتدفقات رؤوس الأموال الدولية وخاصة من قبل فروع البنوك الأجنبية. وبالإضافة إلى ذلك، تم تعزيز التدابير التي اتخذت عام 9 ج. . حيث تم اتخاذ تدابير جديدة للحد من القروض المصرفية بالعملة الأجنبية لمنع زيادة مديونية قطاع الثركات بالعملة الأجنبية. وأيضاً طلب من المؤسسات المالية الحد من عدم توافق آجال الاستحقاق للأصول والخصوم بالعملة vo 
الأجنبيةforeign exchange asset/liability maturity mismatch . وأخيرا، تم تخفيض نسبة العقود

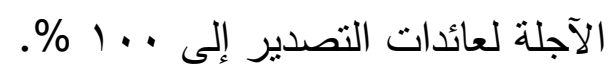
- في يناير 11 إب فرضت السلطات مرة أخري ضريبة على المشتريات الأجنبية لسندات الخزانة. ويالنسبة لمدي كفاءة السياسات التي تم تطبيقها في كوريا الجنويية فيعتبر تأثنر تلاك السياسات

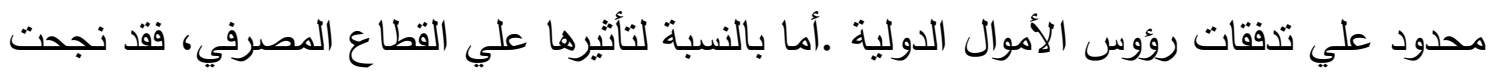
في تقليل الاقتراض قصير الأجل للبنوك من الخارج وذلك كما هو موضح من الثكل (0)

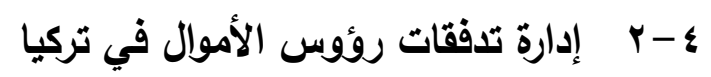

تأثرت نركيا بشكل كبير من الأزمة المالية العالمية (من خلادل التجارة والقنوات المالية) فانخفضت الصادرات بشكل حاد نتيجة الانكماش الاقتصادي في المنافذ التصديرية (أوروبا) وانخفاض التموبل الأجنبي بشكل كبير ، ولكن الاقتصاد التركي تعافى نتيجة اتباع سياسات نقدية تقلل من التقلبات الدورية مع إتخاذ بعض التدابير المالية. وقد ساعدت الأساسيات الاقتصادية الكلية القوية (انخفاض الديون السيادية ومديونية القطاع الخاص) على استدامة التعافي. وكرد فعل للتحدي المتمثل في زيادة عدم الاستقرار المالي نتيجة تدفقات رؤوس الأموال المتقلبة، لجأت تركيا

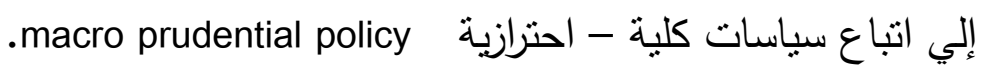

شكل (0) تطور الاقتراض الخارجي قصير الأجل خلال الفترة ه . . r - . • r 


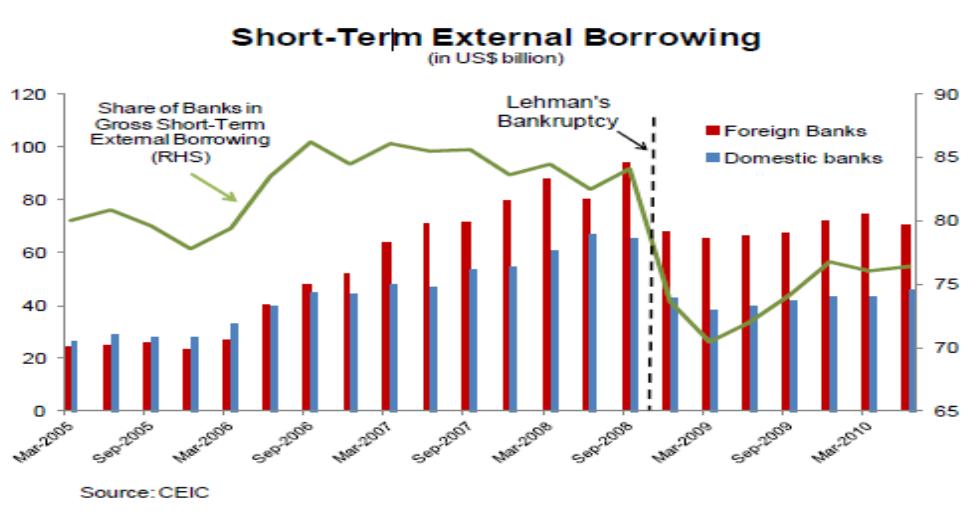

وقد تغيرت طبيعة تدفقات رؤوس الأموال بعد الأزمة المالية العالمية إلي اقتصادات أوروبا الصاعدة وخاصة تركيا حيث أصبحت ذات آجال قصيرة الأجل، وقد استحوذت الاستثمارات

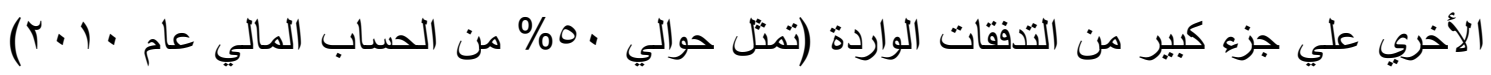
مع إتسامها بدرجة عالية من التذبذب كما هو موضتح في الثكل (7). وقد انخفضت مساهمة

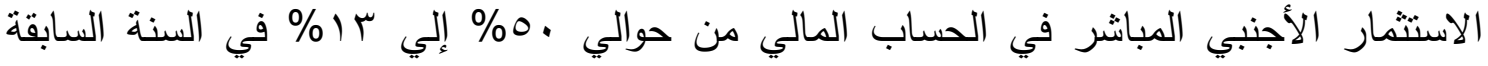
لأزمة المالية.

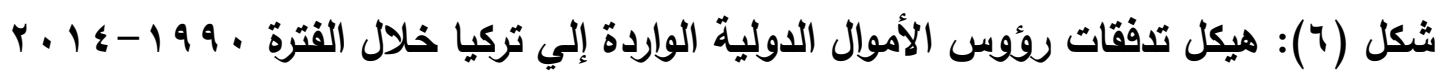

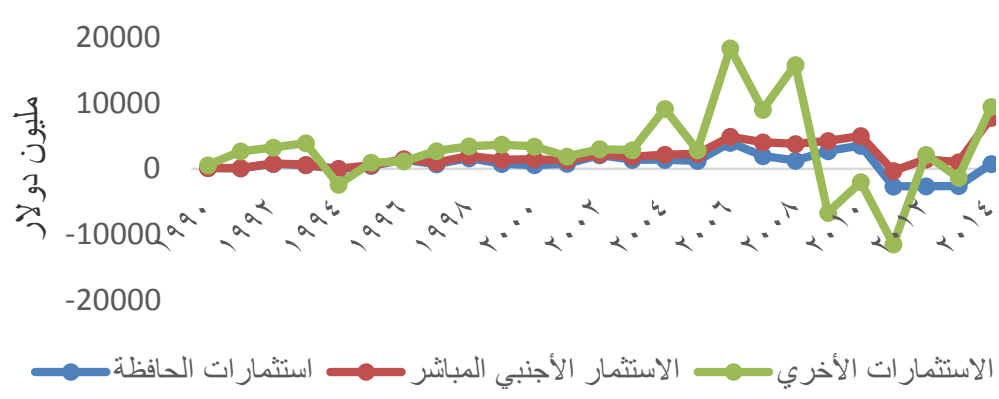

International Financial Statistics, Online Database : المصدر http://data.imf.org/?sk=388DFA60-1D26-4ADE-B505-A05A558D9A42

VV 
وقد أثرت مجموعة من العوامل علي تدفقات رؤوس الأموال الواردة إلي نركيا منل أسعار

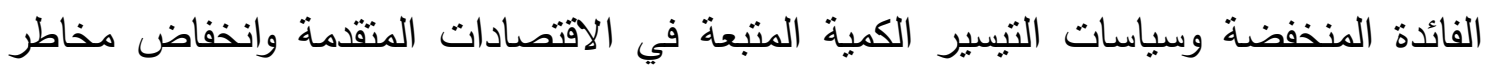

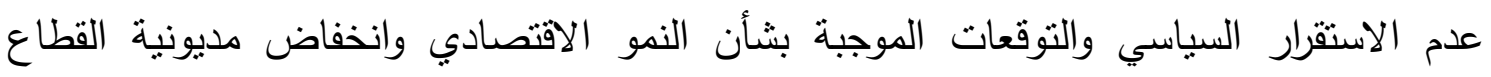
العائلي مقارنة بباقي دول أوروبا إلي زيادة الندفقات.

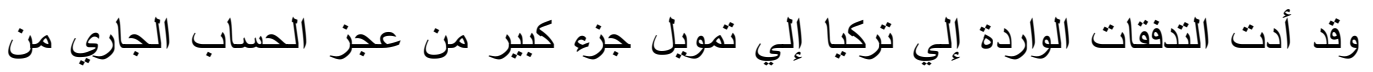

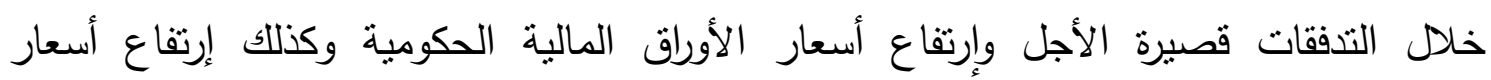

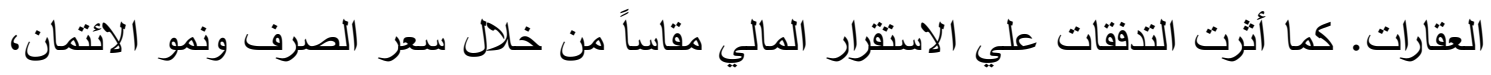

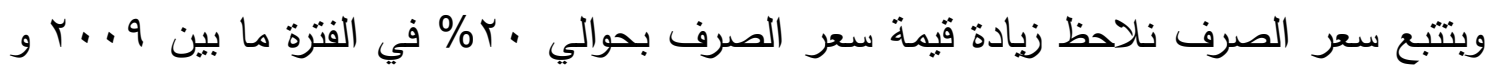

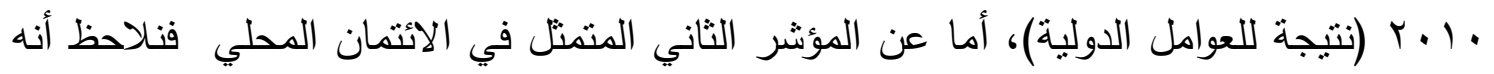

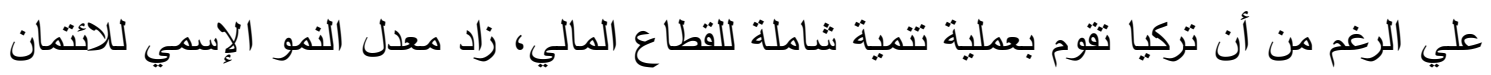

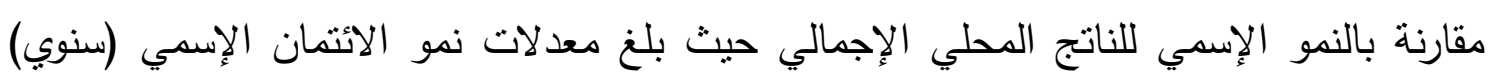

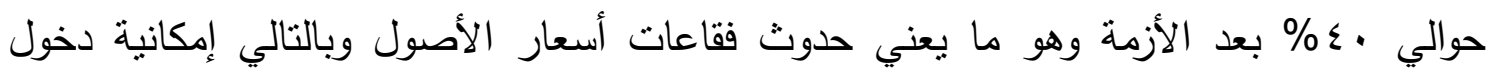

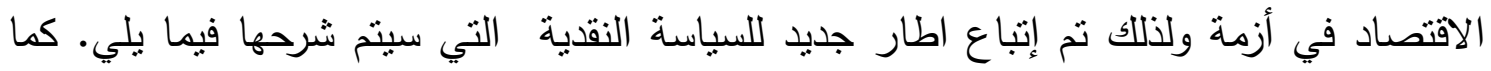

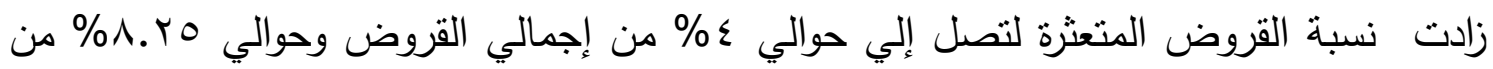
بطاقات الائتمان.

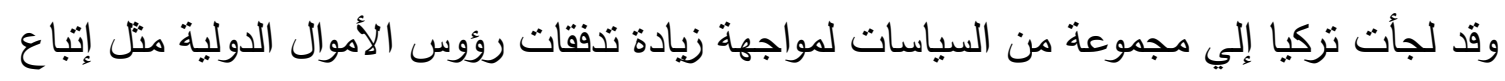

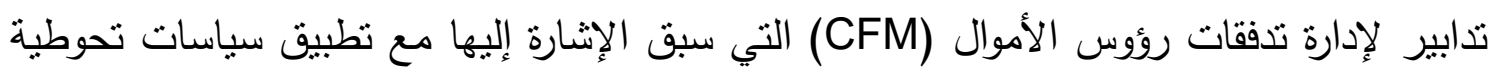

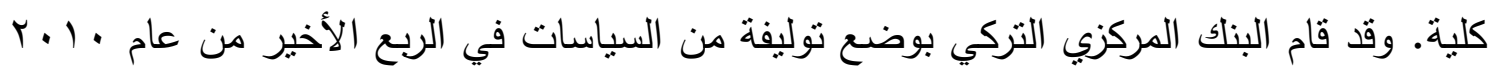

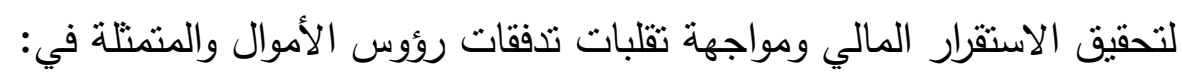

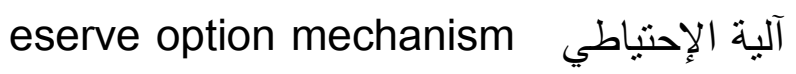


وضع ممر غير متماتل لسعر الفائدة بين الاقتراض لليلة واحدة والإقراض asymmetric interest rate corridor

\section{جدول (r)}

إطار السياسة النقدية في تركيا في ظل رؤوس الأموال الدولية المتقلبة

\begin{tabular}{|c|c|c|}
\hline المنهج الجديد & المنهج القديم & \\
\hline استقرار الأسعار + الاستقرار المالي & تحقيق استقرار الأسعار & الأهداف \\
\hline ممر سعر الفائدة وألية الآحتياطي & سعر الفائدة & الأدوات المتبعة \\
\hline
\end{tabular}

وفيما يلي عرض للسياستين والمزايا المرتبطة بهما في إدارة تدفقات رؤوس الأموال مع تقديم أدلة على كفاءتهما.

\section{interest rate corridor الفائدة}

يقدم البنك المركزي خدمة الإقراض والاقتراض لليلة واحدة (إقراض قصير الأجل للبنوك)

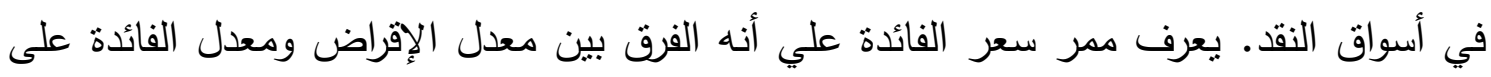

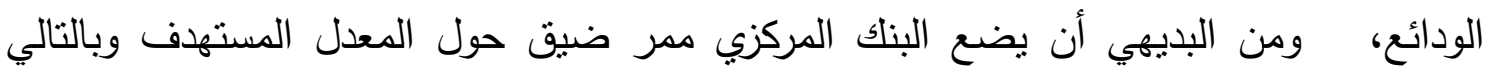

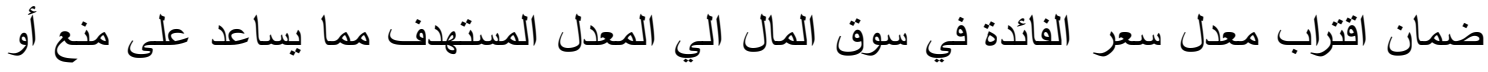

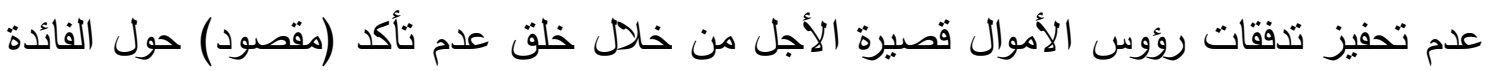

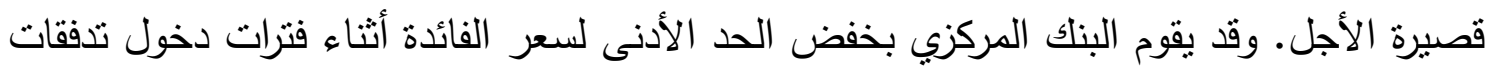

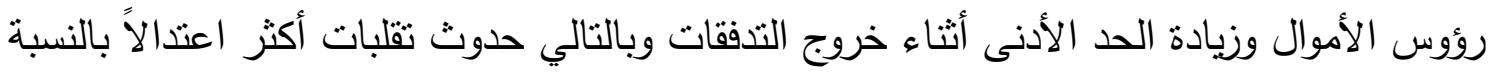

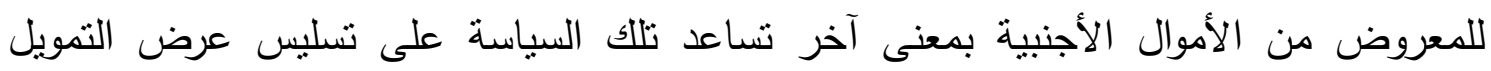

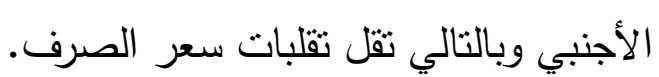

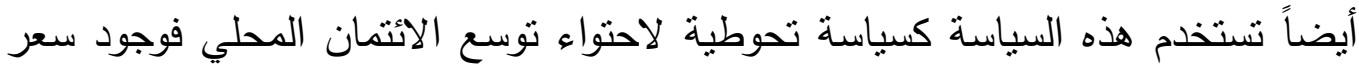

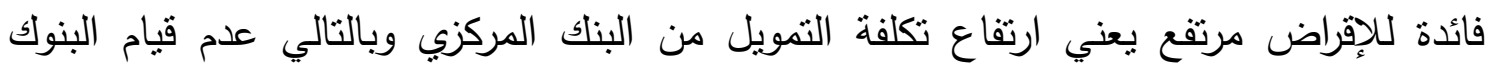

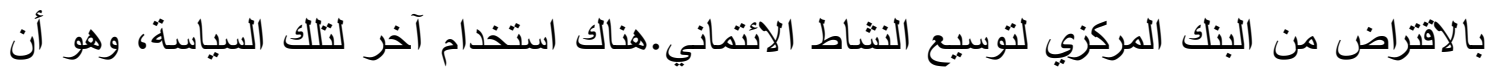


البنك المركزي يستطيع توجيه معدل الفائدة بطريقة غير تقليدية على أساس يومي من خلال

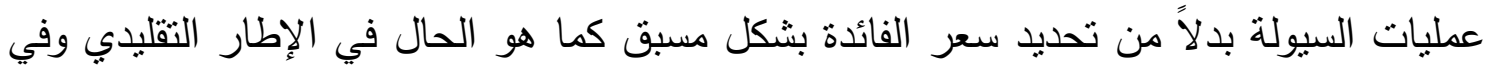

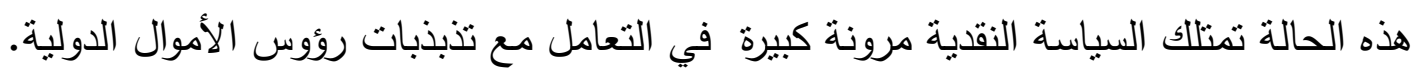

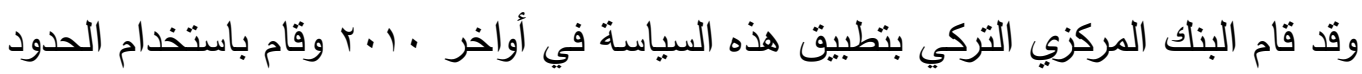

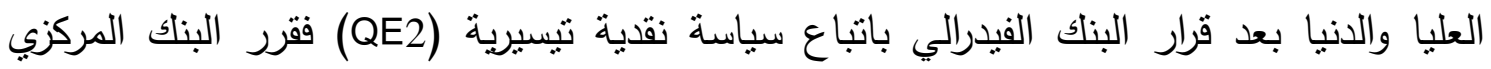

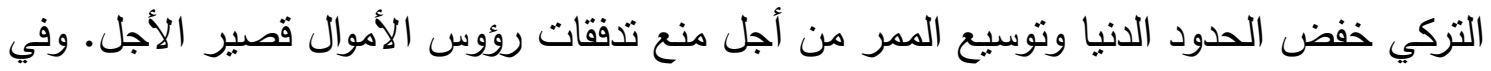

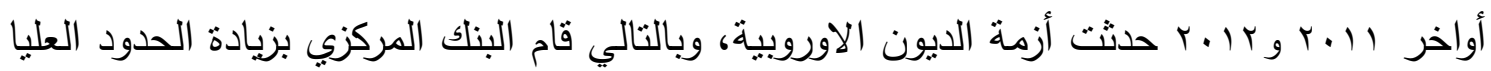

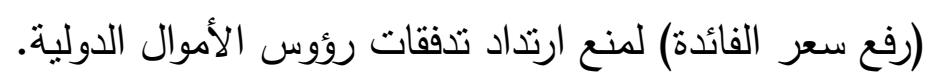

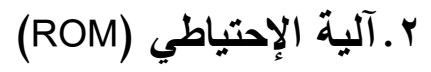

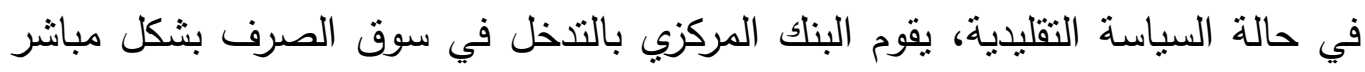

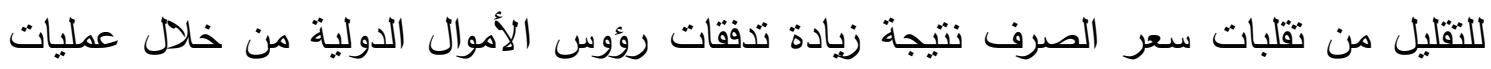

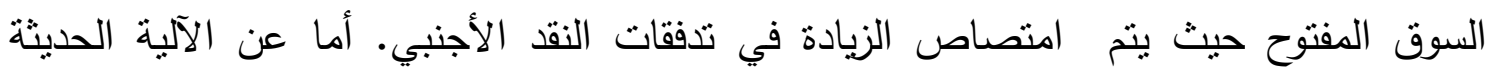

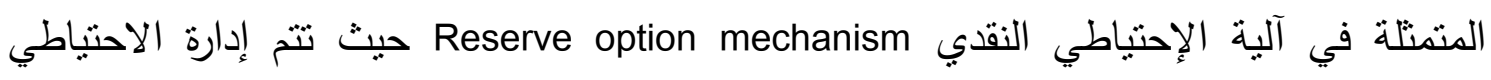

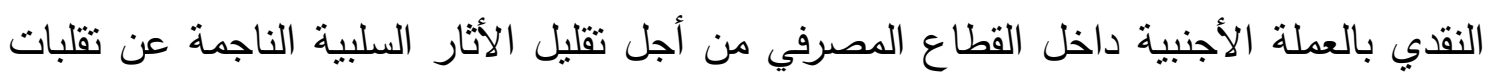

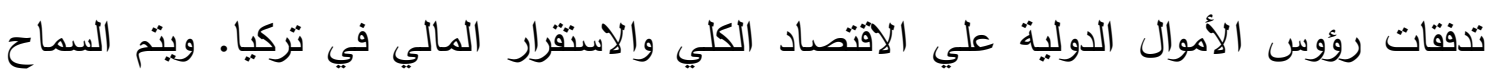

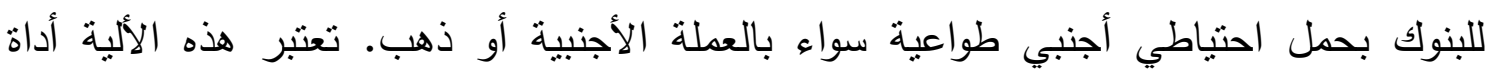

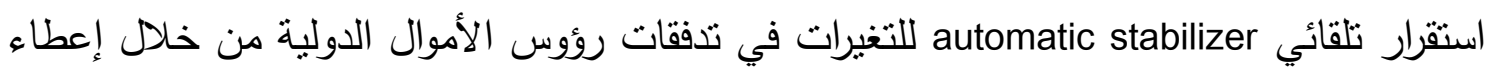

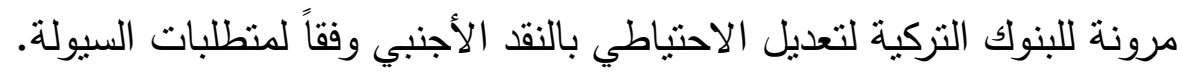

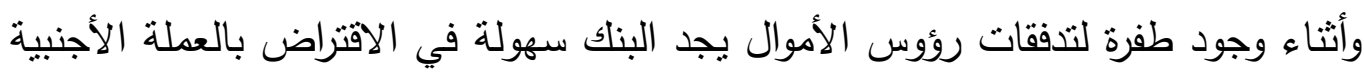

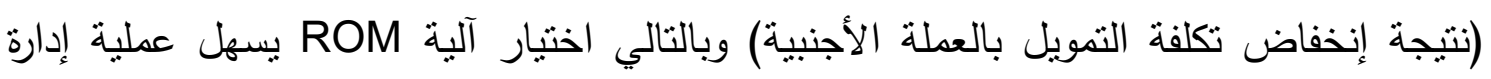

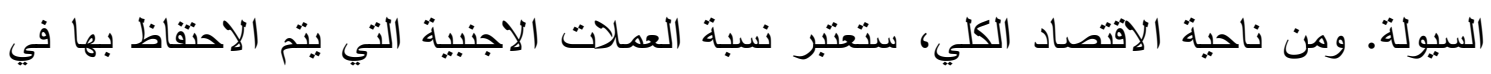


البنك المركزي عامل مساعد لتقليل الضغوط على العملة ونمو الائمان المحلي، وعلاوة على ذلك اللك الإنة

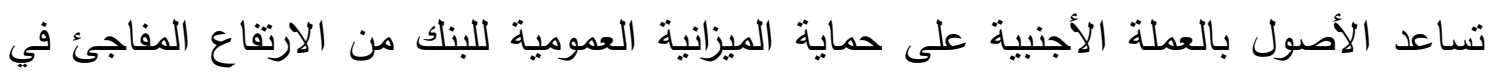
تكلفة تمويل بالعملة الأجنبية.

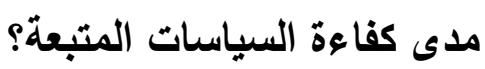

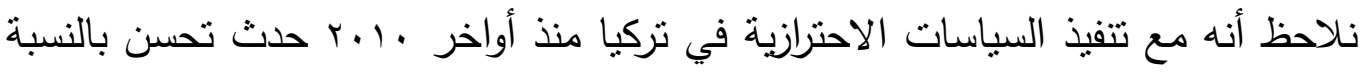

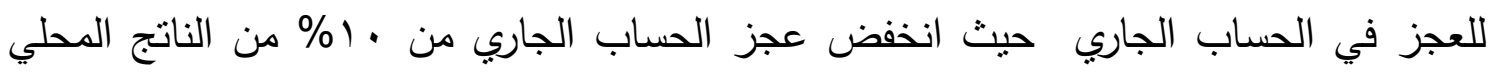

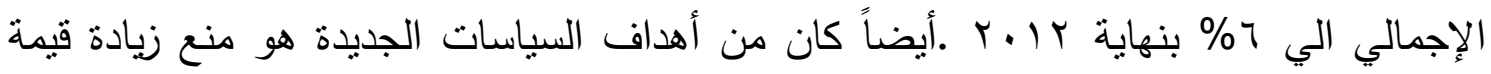

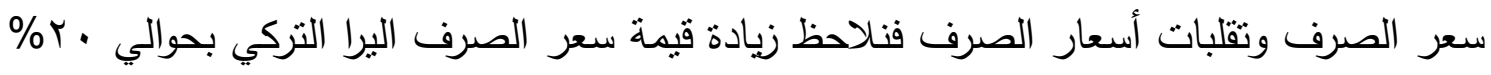

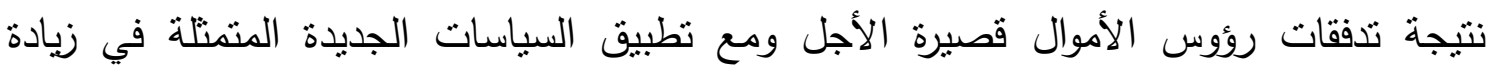

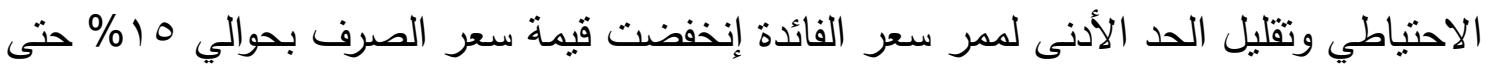

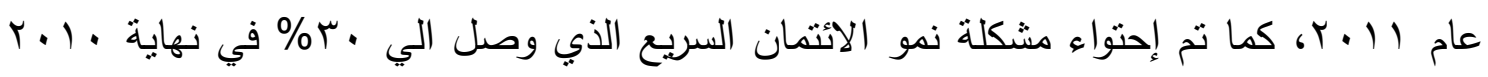

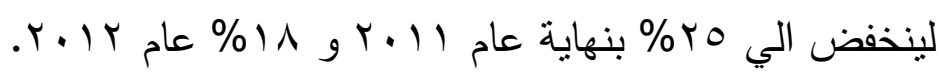

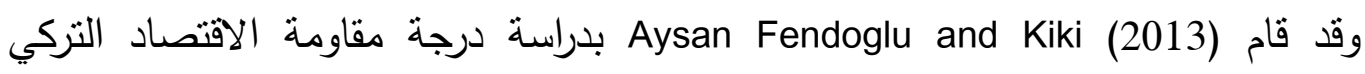

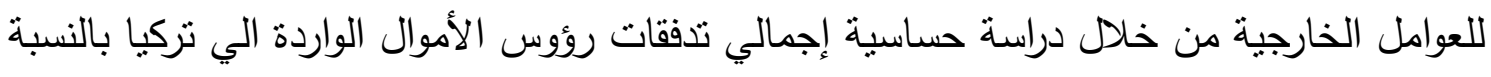

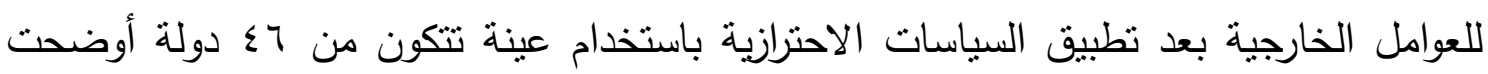

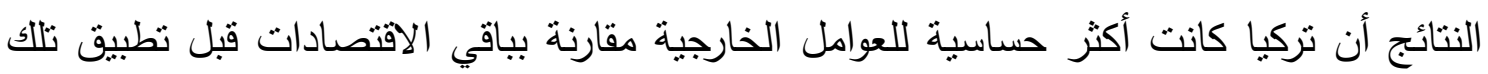
السياسات وأصبحت أقل حساسية بعد تطبيقها. أما عن (2013) Binici et al فقاموا بدراسة العلاقة بين سرعة نمو الايتمان المحلي

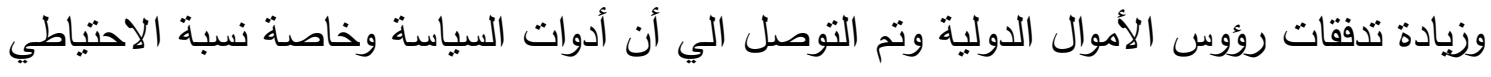

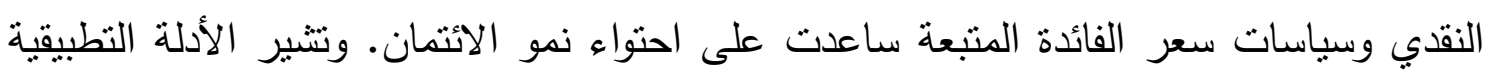

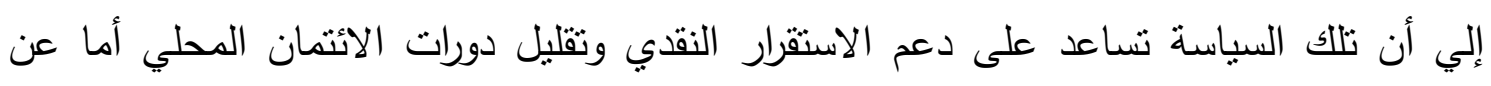
سياسة ROM فقد ثبتت فاعليتها في احتواء الضغط على سعر صرف الليرة دقابل الدولار. 
ع - ب إدارة تدفقات رؤوس الأموال الدولية في مصر

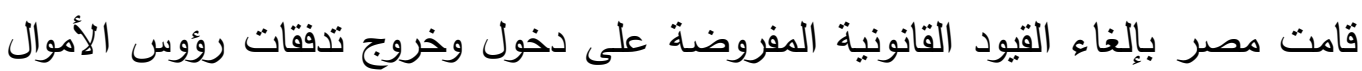

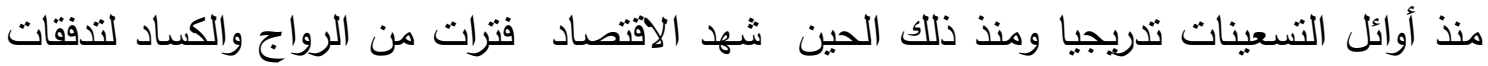

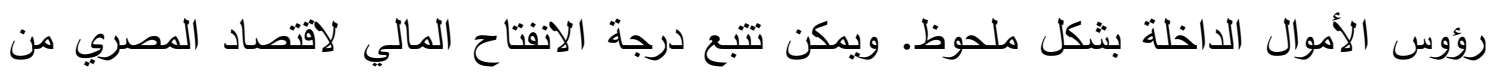

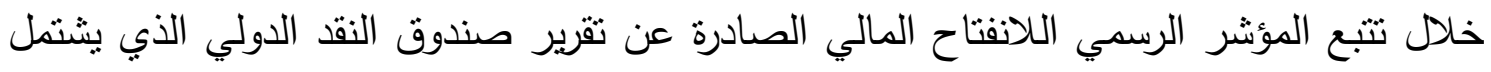
علي القيود والقواعد التي تحكم المعاملات الجارية والرأسمالية والقواعد المفروضة لترية علي المقيمين وغير المقيمن. وقد قام Chinn -lto 'بحساب مؤشر الانفتاح المالي. وكلما ارتفعت قيمة المؤشر

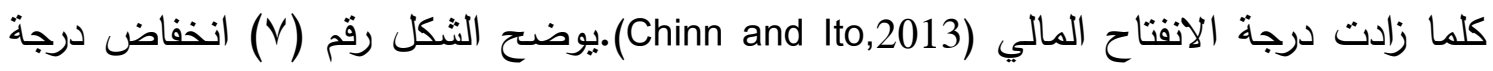
الانفتاح المالي خلال الفترة • 199-1990 أثم ارتفعت قيمة المؤشر مع ظهور أثار التحرير المالي الذي تضمنه برنامج الإصلاح الاقتصادي والتكيف الهيكلي حيث أزيلت القيود علي التعاملات

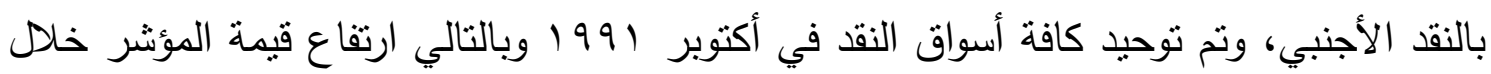

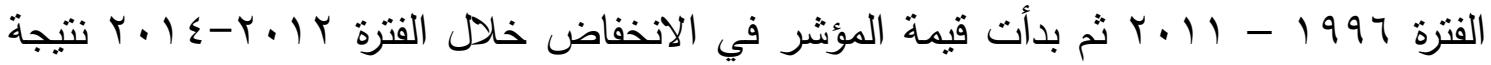

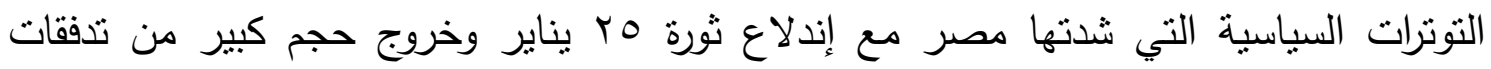

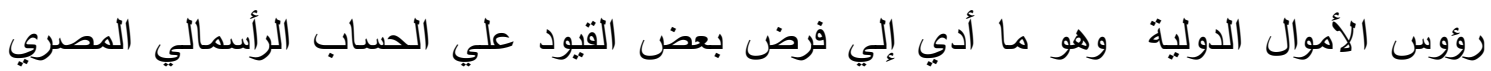
بشكل ملحوظ.

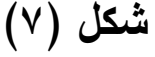

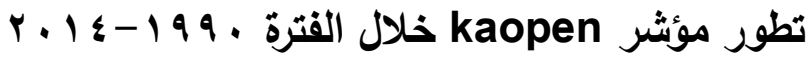

' بُ بمكن الرجوع إلي الدراسة التالية لمعرفة المزيد عن مؤشر KAOPEN الذي حسبة Chinn -Ito لقياس درجة انفتاح الحساب http://www.web.pdx.edu/ ito/kaopen_Chinn-Ito_hi0523.pdf 


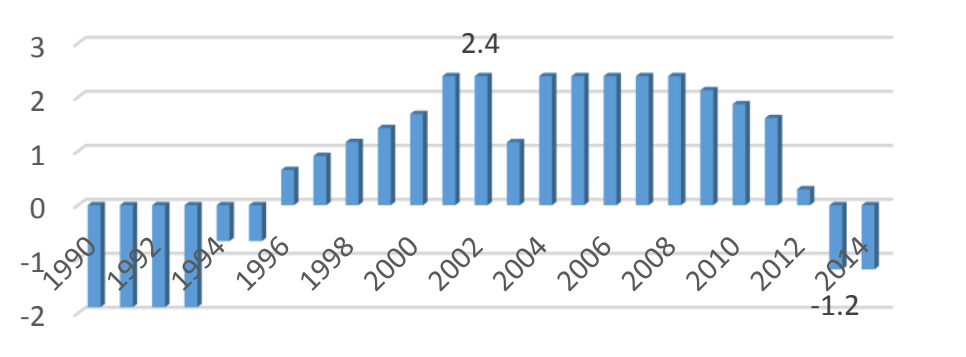

http://web.pdx.edu/ ito/Chinn-Ito_website.htm : المصدر

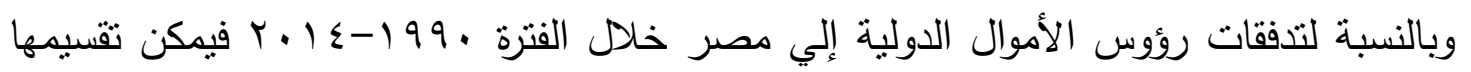

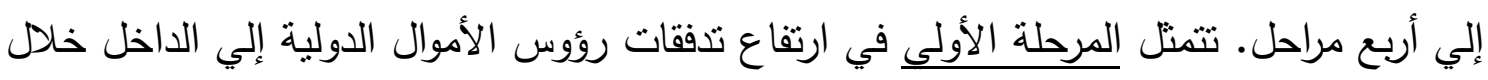

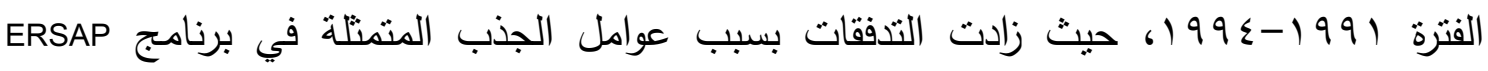
والتحسن في مناخ الاقتصاد الكلي محلياً ( وتحويلات العاملين وانخفاض أسعار الفوات الفائدة العالمية.

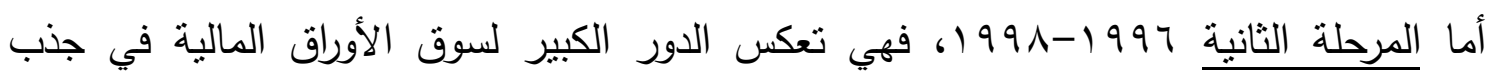
تدفقات رؤوس الأموال إلي مصر (1999 , Al-Mashat) حيث ارتفعت استثمارات الحافظة نتيجة

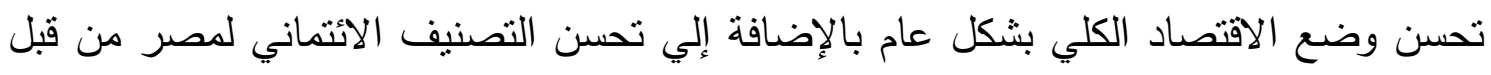

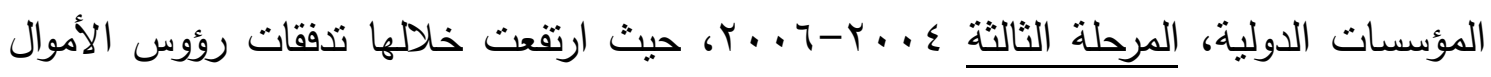

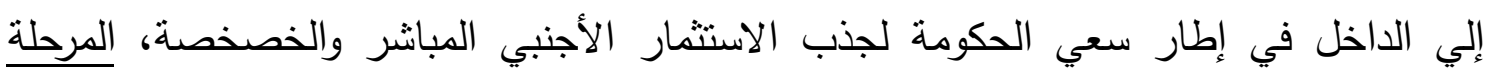

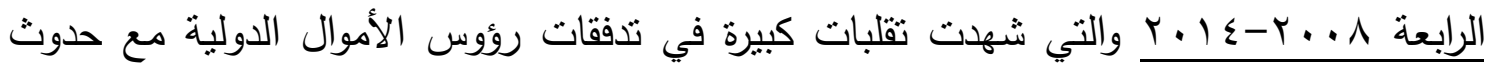

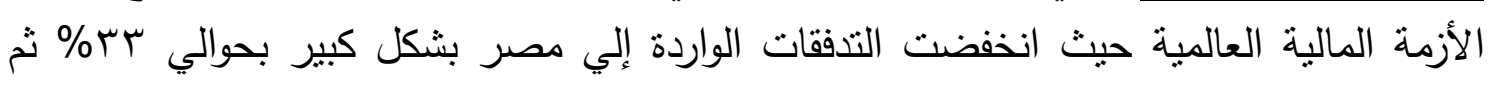

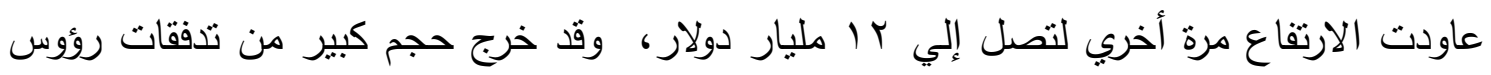

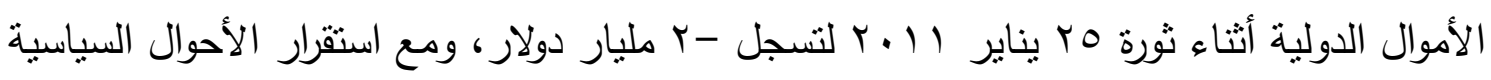

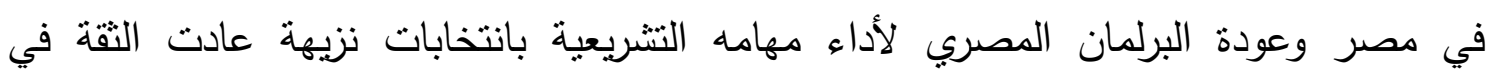
الاقتصاد المصري ومهدت الطريق لعودة الاستثمارات الأجنبية إلي مصرد لـ ويعتبر الاستثمار 
الأجنبي المباشر الوارد إلي مصر أكثر التدفقات استقراراً مقارنة بالتدفقات الأخري المتمثلة في

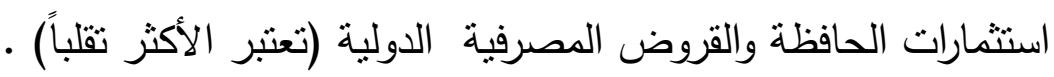
وبتتبع هيكل التدققات الواردة إلي مصر نلاحظ زيادة نسبة بند الاستثمارات الأخري المتمنل في القروض المصرفية الدولية مقارنة بالاستثمار الأجنبي المباشر وتدفقات الحافظة وهو ما يزيد من مخاطر عدم الاستقرار المالي لأنها تتسم بالتقلب الثديد كما هو موضتح من الثكل (^).

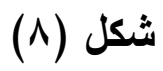

\section{هيكل التدفقات الواردة إلى مصر خلال القترة ـ 99 1 - ـ 1 . r}

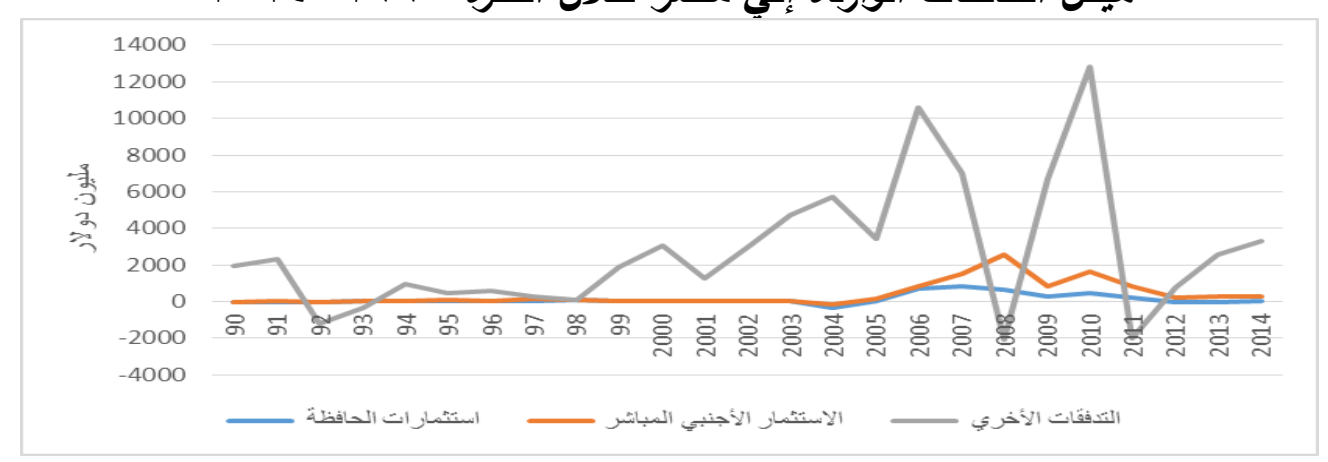

المصدر: : International Financial Statistics, online database

\section{http://data.imf.org/?sk=388DFA60-1D26-4ADE-B505-A05A558D9A42}

وبالتالي تزتد أثناء الأزمات مما يهدد استقرار القطاع المصرفي. وكما هو موضح من

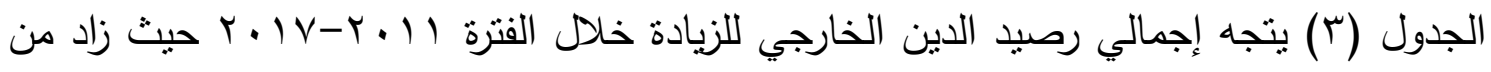

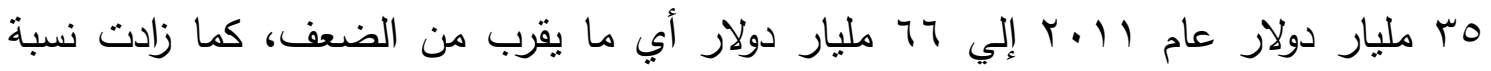

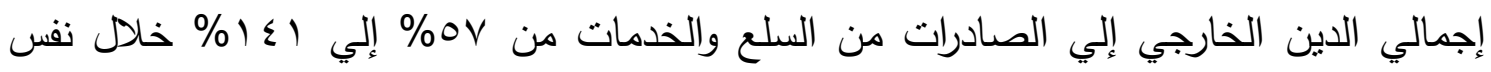
الفترة، وكذلك تتجه نسبة الدين الخارجي إلي الناتج المحلي الإجمالي إلي الزيادة حيث زادت من 


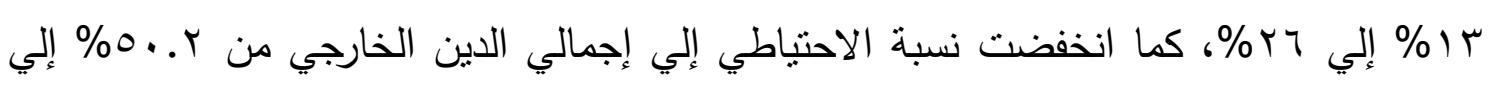

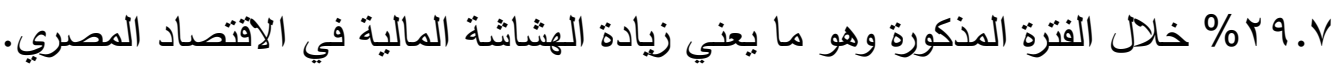
تؤثز مجموعة من عوامل الجذب والطرد في تقلب تدفقات رؤوس الأموال الدولية إلي

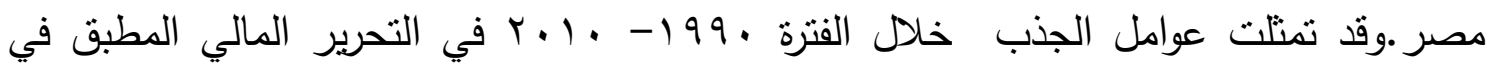
إطار برنامج الإصلاح الاقتصادي والتكيف الهيكلي، وبالأخص تحرير العمليات الرأسمالية في ميزان المدفوعات وإلغاء الحدود العليا لسعر الفائدة، وتطوير سوق لأذون الخزانة وتطبيق سياسة نقدية متتددة مما أدي إلي ارتقاع سعر الفائدة وتدفق المزبد من رؤوس الأموال الدولية. وكذلك تتشيط سوق الأوراق المالية مما أدي إلي جذب تدفقات الحافظة بشكل كبير • أما عن الفترة من

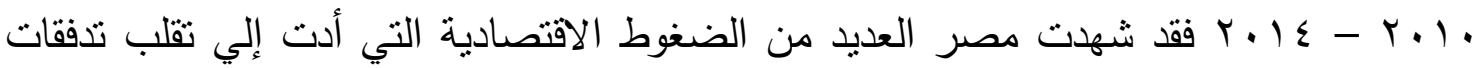
رؤوس الأموال الدولية الواردة إلي مصر، فمثلا زادت الضغوط المالية الخارجية وتعديل سعر الصرف حيث وصل عجز الحساب الجاري لأكثر من الضعف إلى نحو 1.9 مليار دولار على أساس سنوي خلال الفترة (يوليو - ديسمبر) 10 . ب، وذللك نتيجة انخفاض عائدات صادرات السلع، وانخفاض عائدات السياحة وعائد قناة السويس، مع تقلص الدعم المالي من دول مجلس التعاون الخليجي، وانخفاض قيمة التدفقات الأجنبية. وانخفض العائد السياحي من 7.2 مليار

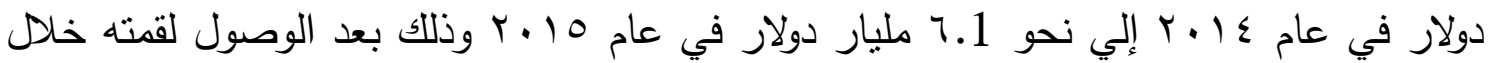
عام • 1 • ليسجل نحو 0.ب مليار دولار قبل انتفاضات الربيع العربي، وقد تعرض العائد السياحي للانخفاض مرة أخري خلال عام 1 ـ.r. ووفقاً للبنك المركزي المصري فقد سجل عدد

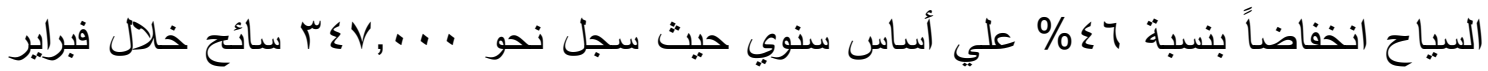
7 1 • r، مع العلم أن عدد السياح كان قد بدأ في التحسن بعد أزمة ظلت خمس سنوات، ويواجه قطاع السياحه عاماً صعباً بالإضافة إلي تأثير الأحداث السلبية الأخرى ومنها تحطم الطائرة الروسية في منتصف مايو 17 .r. وقد زاد صافي تدفقات الاستثمار الأجنبي المباشر إلي نحو 


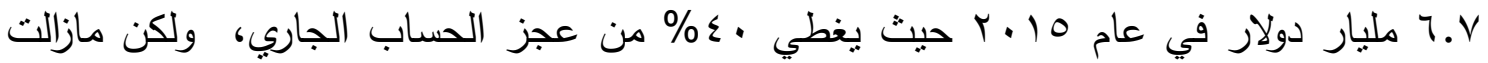
مصر تحتاج لتدفقات نقدية لتغطية العجز • وقد ساعد دعم دول مجلس التعاون الخليجي علي زيادة الاحتياطي النقدي لدي البنك المركزي خلال شهر أبريل من نفس العام 10 . ب ولكن تعرضت هذه الاحتياطيات للضغوط خلال النصف الثاني من العام. شكل (9)

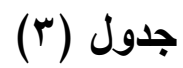

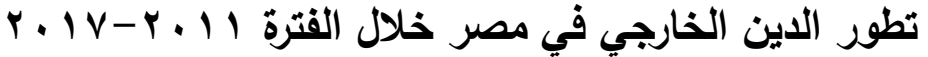

\begin{tabular}{|c|c|c|c|c|c|c|c|}
\hline $\begin{array}{l}r+\text { PV } \\
\text { (تقيري) }\end{array}$ & r.14 & $r+10$ & $r+1 \varepsilon$ & $r \cdot I r$ & $r .1 r$ & r. Ir & رصيد الديون الخارجية \\
\hline 66,416 & 58,001 & 44,607 & 39,624 & 44,444 & 39,997 & $r 0,1 \leqslant 0$ & الإجمالي (مليون دولار) \\
\hline 53,094 & 49,398 & 39,288 & 34,980 & 40,232 & 31,939 & 30,724 & (مليون دولار) الأجل \\
\hline 99 & 71 & 43 & 21 & 12 & 20 & 16 & 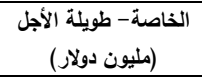 \\
\hline 7,724 & 3,592 & 1,259 & 1,302 & 1,384 & 1,381 & 1,379 & 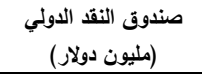 \\
\hline 5,499 & 4,940 & 4,017 & 3,321 & 2,816 & 6,657 & 3,026 & $\begin{array}{c}\text { قصيرة الأجل (مليون) } \\
\text { (مليون }\end{array}$ \\
\hline 140.9 & 127.3 & 80 & 59.2 & 70.7 & 60.3 & Or & من السليع والخذمات(\%) صادرات \\
\hline 26.1 & 21.5 & 14.8 & 13 & 15.7 & 14.8 & 13.6 & إلجمالي الدين / الناتج الإجمالي (\%) \\
\hline 29.7 & 32.1 & 34.7 & 36.5 & 36.3 & 37.3 & 50.2 & الإحتياطي / / إجمالي \\
\hline
\end{tabular}

المصدر: .The Economist Intelligence Egypt, Country Risk Service , 2016

Unit

(9) شكل (9) (1)

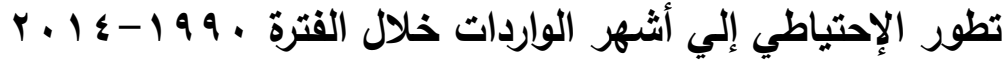




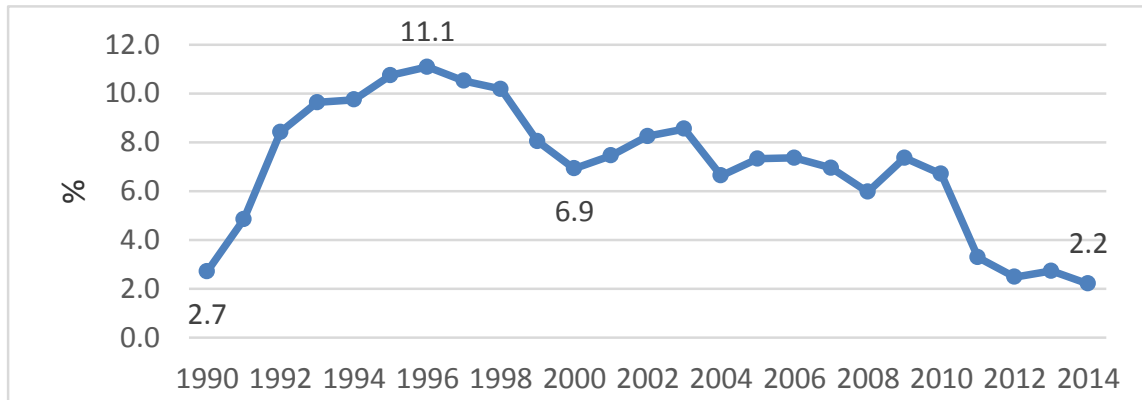

World Development Indicators , Online Database : المصدر

ولجأ البنك المركزي المصري في مارسج 1 • ب إلى سياسة خفض قيمة العملة المحلية من

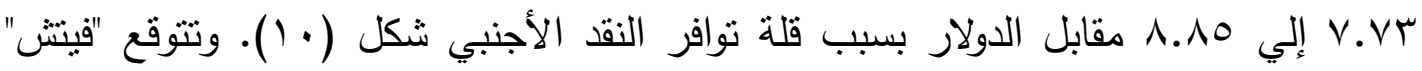
وصول عجز الحساب الجاري إلى ء.ء ٪ كنسبة من الناتج المحلي الإجمالي خلال عام 1 ـ ؟، وذلك نظراً لانخفاض النقد الأجنبي كغطاء للواردات، وضعف سعر صرف، وارتفاع الرسوم الجمركية وتعقيدات لوائح الانتيراد وانخفاض أسعار النفط، وتفترض أيضاً تدهوراً كبيراً في ميزان الخدمات. وقد تحسن وضع ميزان المدفوعات بسبب الدعم المالي المُقدم من دولة الإمارات العربية المتحدة والمملكة العربية السعودية. ومع ذلك، فإن الاحتياطي النقدي غطي تمويل المدفوعات الخارجية لنحو ثلاثثة أثنهر • مع العلم أن هذه الأرقام لا تأخذ في اعتبارها اتفاق قرض صندوق النقد الدولي.

أثز أيضاً التصنيف الائتماني غير المستقر لمصر من قبل مؤسسات التمويل الدولية علي زيادة تقلبات تدفقات رؤوس الأموال الدولية الواردة حيث احتلت مصر التصنيف الائتماني C وفقاً لتقييم المخاطر السيادية ومخاطر العملة ومخاطر القطاع البنكي والمخاطر السياسية ومخاطر الهيكل الاقتصادي ومخاطر الدولة، جدول (ع) (EIU,2016).

$$
\text { شكل ( ) (1.) }
$$

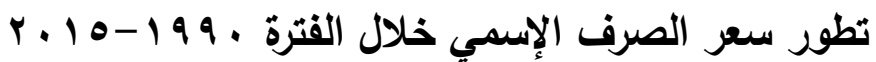




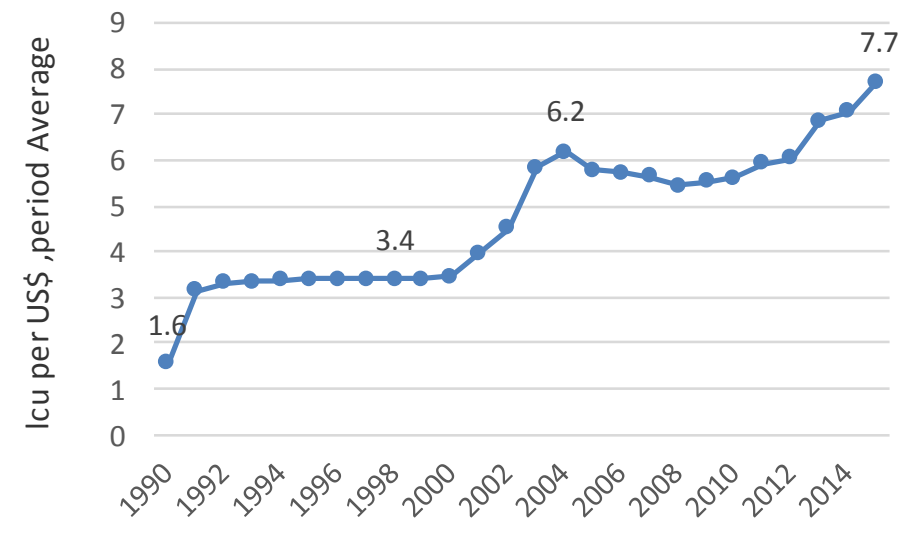

World Development Indicators , Online Database : المصدر

جدول (؛ ( )

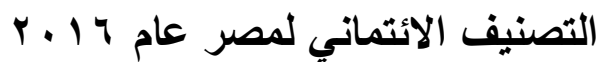

\begin{tabular}{|c|c|c|c|c|c|c|}
\hline مخاطر الدولة & الإقتصادي & مخاسية & القخاطر & مخلة & مخاطر & أغسطس \\
\hline $\mathrm{CCC}$ & CCC & $\mathrm{CC}$ & $\mathrm{CCC}$ & $\mathrm{CC}$ & CCC & \\
\hline
\end{tabular}

ويتفصيل المخاطر الرئيسية التي تتعرض لها مصر نجد ثلاثة أنواع من المخاطر:

أولاً: المخاطر السبادبية:

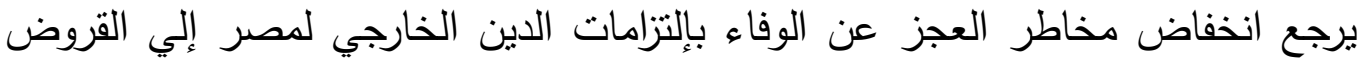

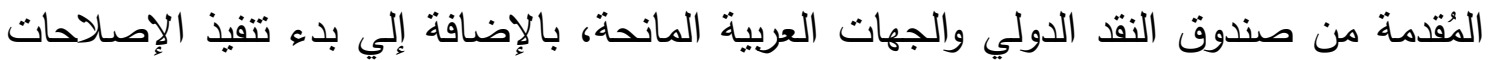

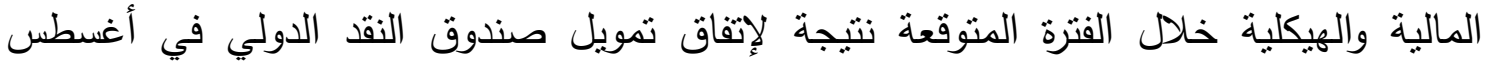




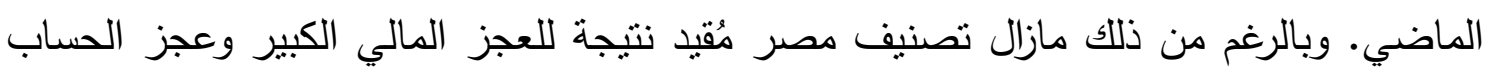

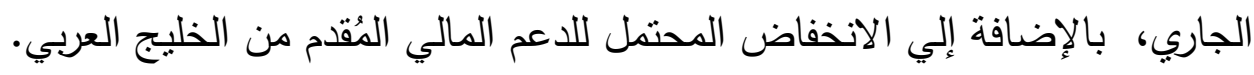
ثانباً: مخاطر العملة:

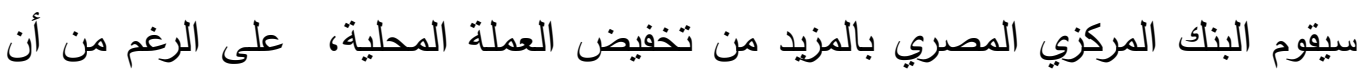

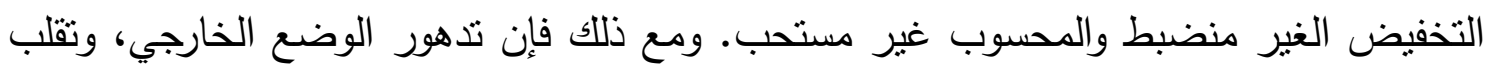

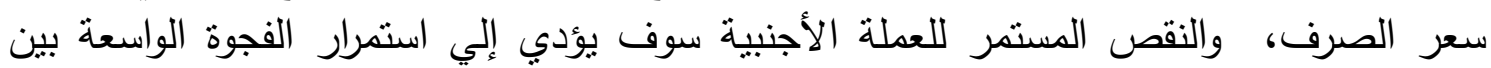
سعر الصرف الرسمي وسعر الصرف في السوق الموازي (السوداء) خلال الفترة المقبلة.

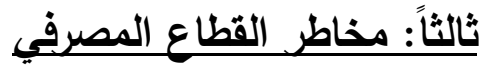

يعاني القطاع المصرفي من اختلالات هيكلية عميقة نظهر بوضوح في الوضع السلبي

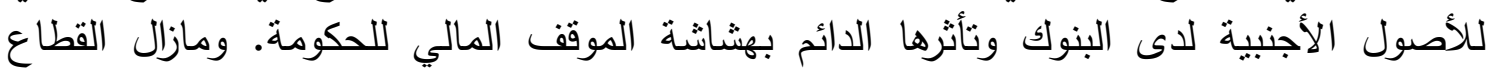

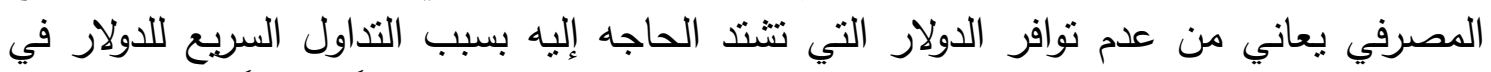

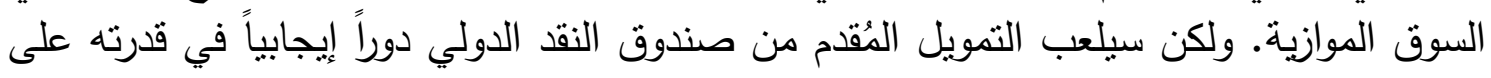

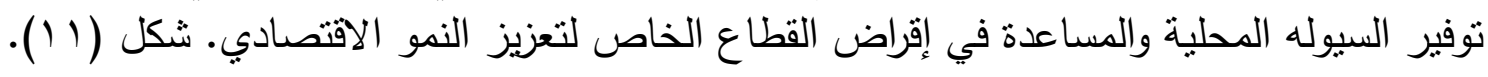

\section{شكل (11)}

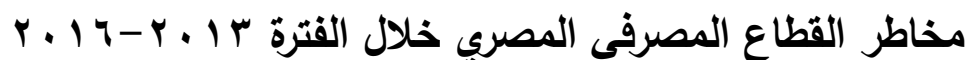

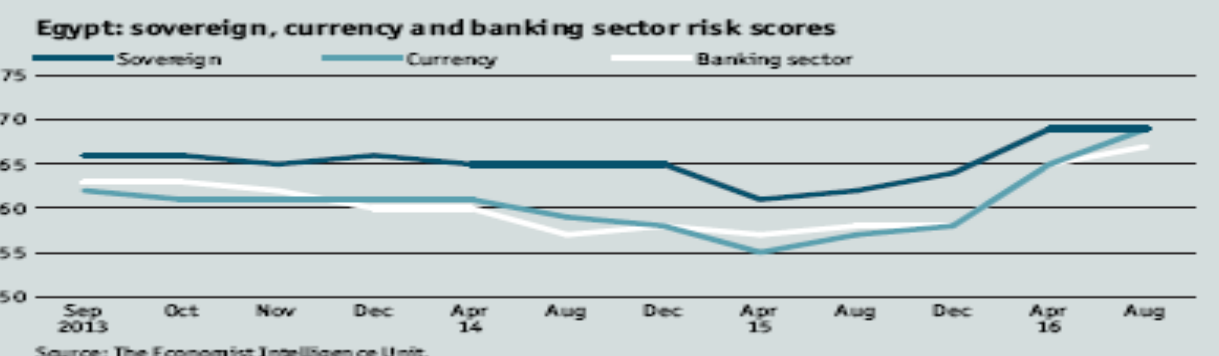

$\wedge q$ 
المصدر: The Economist Intelligence Unit , sept 2016, Country Risk Service

وبتفصيل مؤشرات المخاطر الرئيسية التي تتعرض لها مصر بالمقارنة بدول الثرق الأوسط وشمال

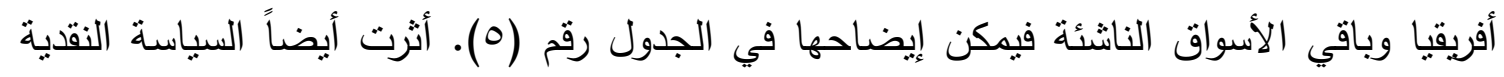

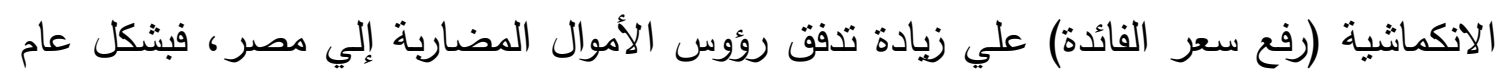
توجه السياسة النقدية إلي حد كبير لكبح جماح التضخم المنوقع الناتج عن الانخفاضات الأخيرة

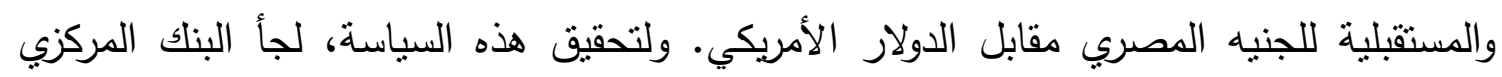

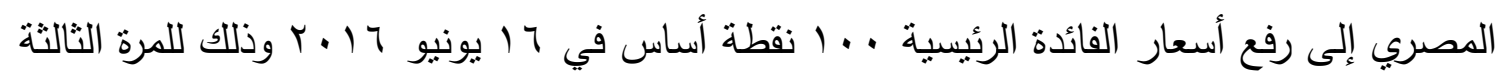

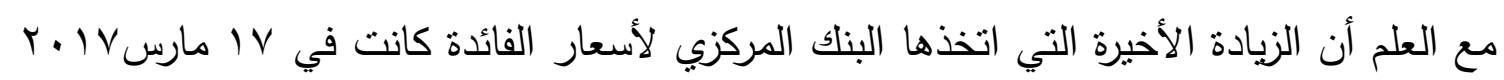

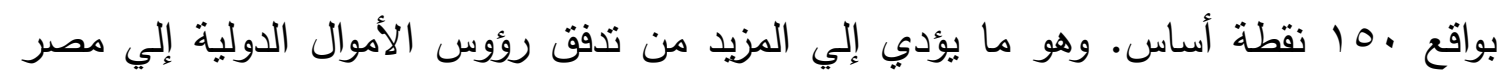
نتيجة

جدول (0)

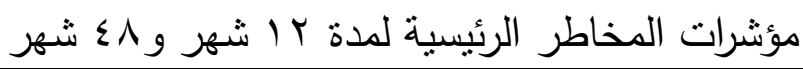

\begin{tabular}{|c|c|c|c|c|}
\hline متوسط الأسواق & متوسط الثرق الأوسط & تصنيف متوسط & مصر & $\%$ \\
\hline 纟..Y & $T . . V$ & or.1 & qr.. & إجمالي الدين العام / من الناتج المحلي الإجمالي \\
\hline$\varepsilon \cdot . \varepsilon$ & ro.乏 & $r \leqslant . r$ & iv.. & إجمالي الدين الخارجي / من الناتج المحلي الإجمالي \\
\hline$\cdots$ & $\cdots$ & $1 . r$ & $\cdots$ & الفائدة والمتأخرات ان وجدت / من إجمالي الدين الخارجي \\
\hline 70.0 & $\sum r . r$ & AV.V & VT.V & صافي الدين الخارجي / من الصادرات \\
\hline$-\cdot r$ & 1.1 & $-\cdot . r$ & $-\cdot 1$ & 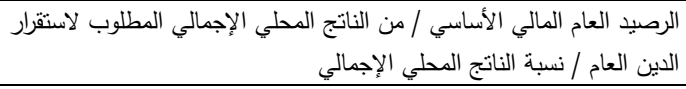 \\
\hline 111.2 & $1 . r . \varepsilon$ & 01.0 & 01.1 & احتباطيات النقد لأجنبي/ من إجمالي منطلبات التمويل الخارجي \\
\hline$r \leq 7 . r$ & TVR.r & rฯq.V & rฯq.1 & احتباطيات النقد لأجنبي/ الدين الخارجي قصبر الأجل \\
\hline
\end{tabular}




$$
\text { أمانى عبد الوهاب }
$$

المجلة المصرية للتنمية والتخطيط

\begin{tabular}{|c|c|c|c|c|}
\hline .0 & $-\varepsilon .0$ & $-\vee .1$ &.$r$ & احتياطيات النقد لأجنبي (متغيرة علي مدار الستة أشهر الأخيرة) \\
\hline $1+r .4$ & -1.7 & rv. & -YY.. & موقف البنوك من الأصول الأجنبية / إجمالي قيمة الأصول الأجنبية \\
\hline r.r & $\varepsilon .0$ & $1 . \mathrm{V}$ & -1. & الإِتمان المصرفي للقطاع الخاص / من الناتج المحلي الإجمالي (منغير في الـ \\
\hline$\cdots$ & -9.9 & $-1 Y .9$ & $1 \leqslant .9$ & سوق الأسهم ( متغير علي مدار الــr شهر الأخيرة) \\
\hline \multicolumn{5}{|c|}{ علي مدار الـ r ا شهر الأخيرة } \\
\hline..$\wedge$ & -1.9 & 1.1 & $\cdot . r$ & متوسط القيمة الحقيقية للأموال - أسعار فائدة السوق \\
\hline$-r . \varepsilon$ & $-11 . r$ & -0. & $-11 . \mathrm{V}$ & التوازن المالي/من الناتج المحلي الإجمالي \\
\hline $\mathrm{v} .9$ & $11 . r$ & $\varepsilon . \wedge$ & Ir.r & الفائدة المدفوعة علي الدين العام / من إيرادات الحكومة \\
\hline-4.0 & $-1 Y .0$ & $-\wedge . \wedge$ & $-11 . \wedge$ & نمو الصادرات بالدولار الأمريكي \\
\hline$-r .1$ & $-\varepsilon . V$ & $-\wedge .1$ & $-7 . \varepsilon$ & رصيد الحساب الجاري / من الناتج المحلي الإجمالي \\
\hline $1 . . v$ & $1 . .1$ & 1.99 & 8.7 & استحقاق خدمة الدين / من الصادرات \\
\hline r.V & r.9 & r.r & $1 . \varepsilon$ & إستحقاق الفائدة / من الصادرات \\
\hline 0.1 & 7.7 & r.A & r.. & متوسط تغطية الواردات ( بالأشهر) \\
\hline 0.1 & $r .0$ & V.£ & $\varepsilon .4$ & قروض البنوك - الإيداع ( بالنقاط المئوية ) \\
\hline$\wedge . \wedge$ & A.r & $1 \leqslant . V$ & 10.9 & التغير في الإتتمان المصرفي للقطاع الخاص \\
\hline \multicolumn{5}{|c|}{ علي مدار الـ ^ ؛ شهر الأخيرة } \\
\hline$-r . r$ & $-Y .9$ & -9.4 & $-r . Y$ & متوسط ميزان الحساب الجاري / من الناتج المحلي الإجمالي \\
\hline r.o & $r . \wedge$ & r. & r.A & متوسط نمو الناتج المحلي الإجمالي \\
\hline r.9 & r.r & 7.0 & $1 \cdot . r$ & متوسط معدل التضخم \\
\hline r.乏 & $1 T . \varepsilon$ & A.r & $1 . .7$ & التغير في سعر الصرف الحقيقي المرجح تجارياً \\
\hline
\end{tabular}

المصدر: The Economist Intelligence Unit , sept 2016, Country Risk Service وجود فروق سعر فائدة كبيرة بين مصر والاقتصاديات المتقدمة وخاصة الولايات المتحدة

التي اتبعت سياسة التيسير الكمية منذ الأزمة المالية العالمية 2 Quantitative easing 1 and وبالتالي من الضروري دراسة أثز رفع أسعار الفائدة الأمريكية من جانب مجلس الاحتياطي الاتحادي (البنك المركزي الأمريكي) من عام VI • ع علي تدفقات رؤوس الأموال الدولية الواردة

أما عن تدهور وضع المالية العامة في مصر فقد ساهم بشكل كبير في انخفاض تدفقات رؤوس الأموال الدولية الواردة نتيجة عدم الثقة في الاقتصاد، ولذلك تسعي الحكومة إلي تخفيض

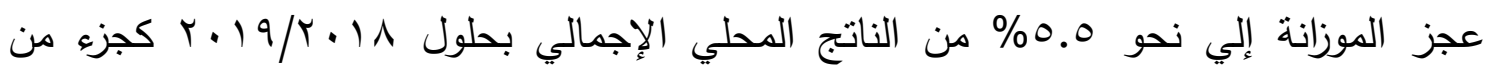
اتفاقية تمويل صندوق النقد الدولي. وغالباً قد لا يتحقق هذا الهدف خاصة مع التوترات السياسية

\section{1}




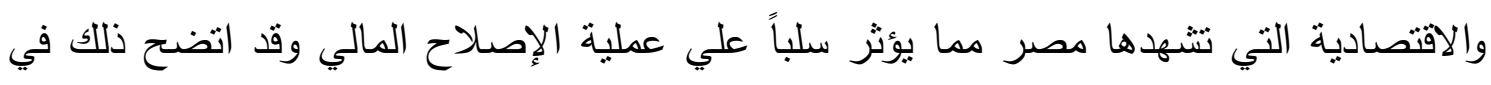

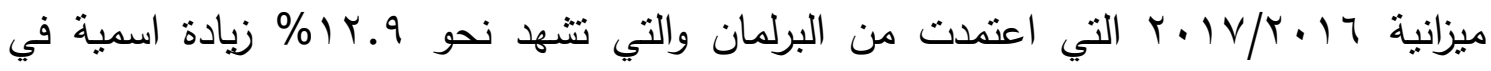

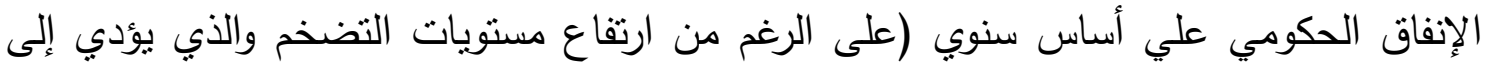

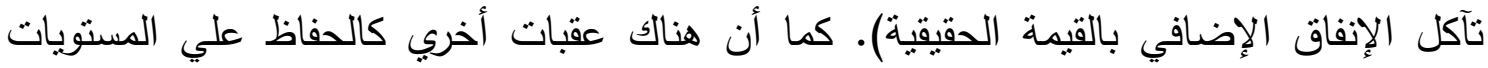

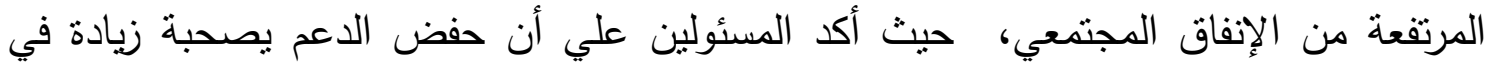

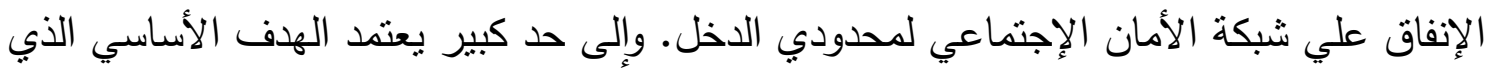

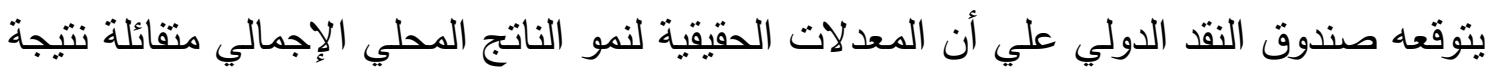

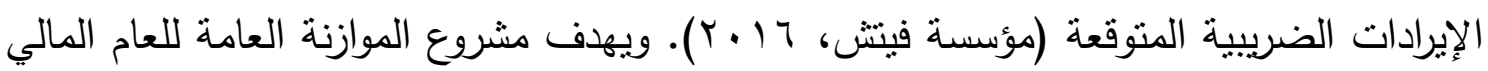

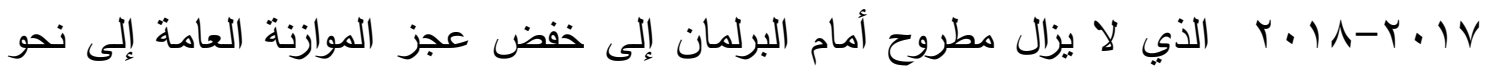

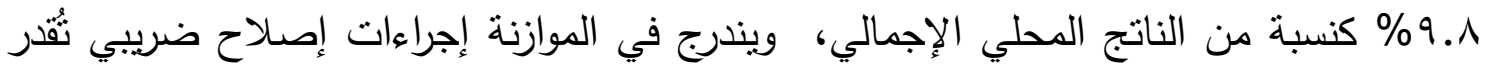

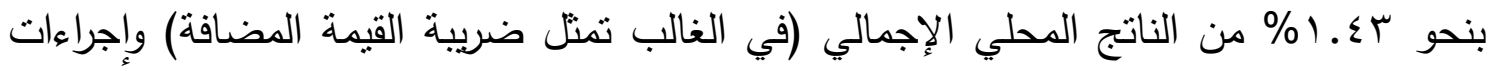

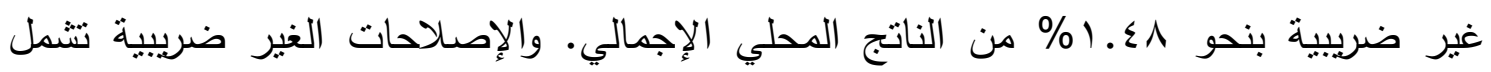

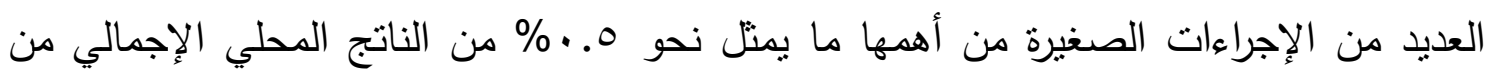
الإصلاحات في دعم الوقود والكهرباء.

وفي الواقع فإن هذه الموازنة تم بنائها على أساس الزيادة الكبيرة لمدفوعات الفائدة، وأيضاً

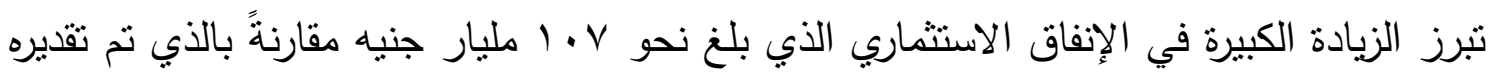

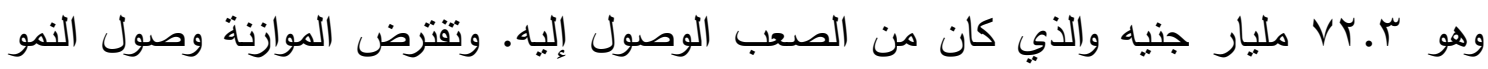

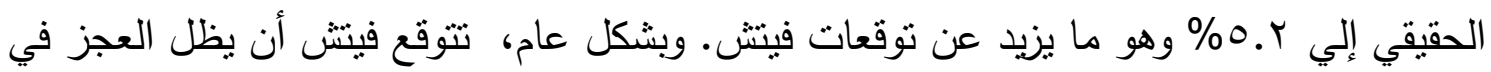

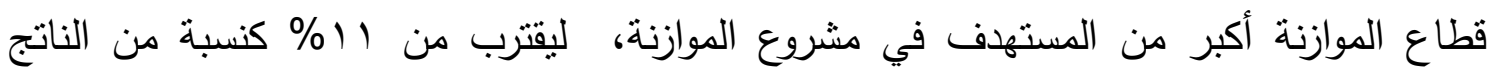
المحلي الإجمالي. 
وقد ارتفع حجم الدين العام للحكومة إلى نحو (919\% كنسبة من الناتج المحلي الإجمالي خلال

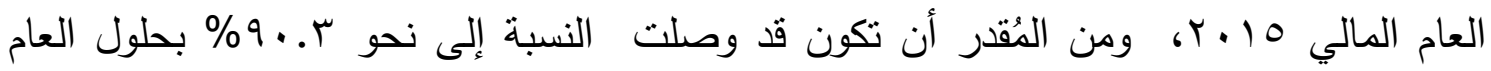

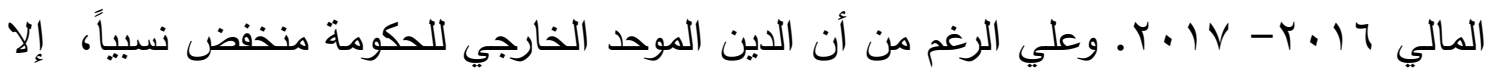

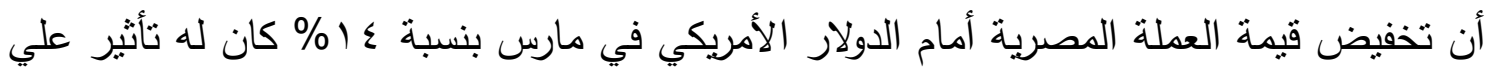

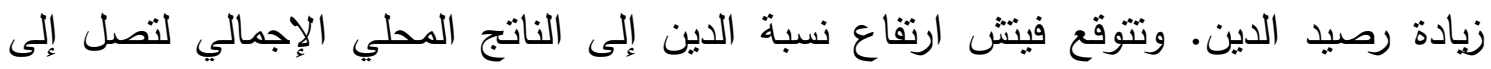

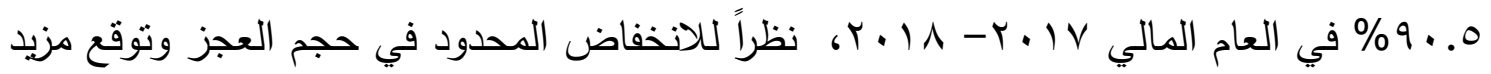
من الانخفاض في سعر الصرف للجنيه المصري.

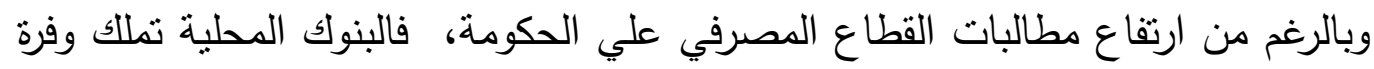

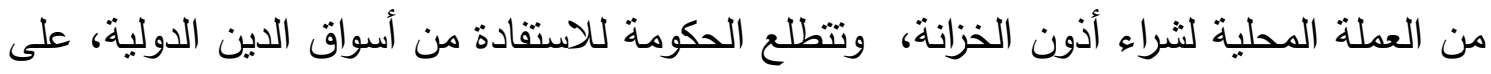

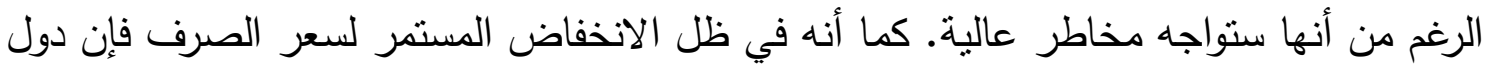

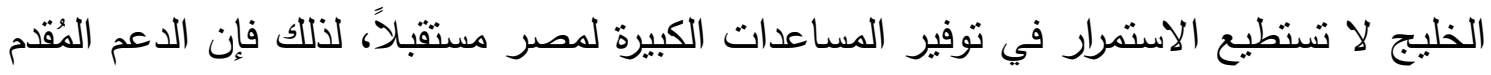

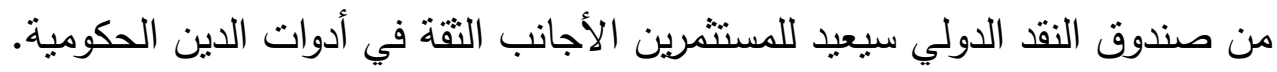

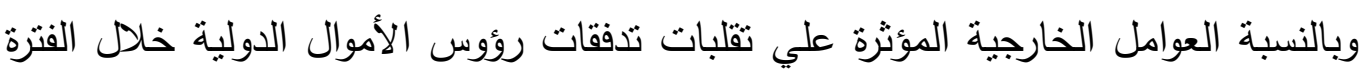

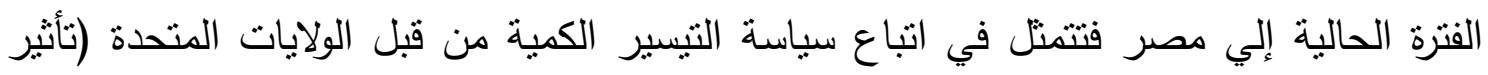

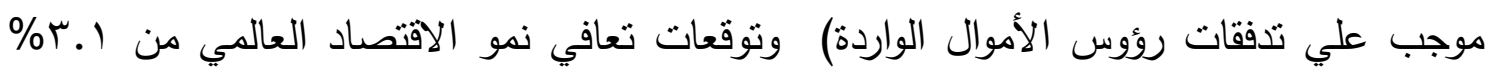

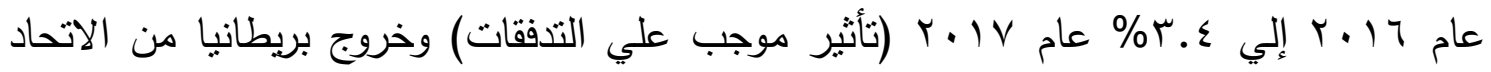

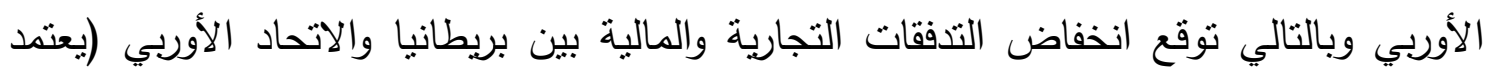

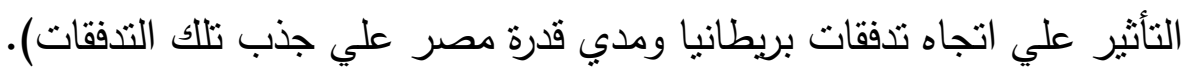

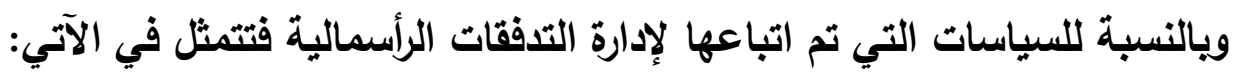

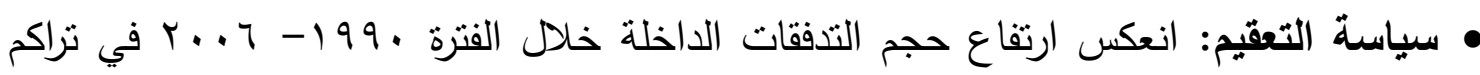

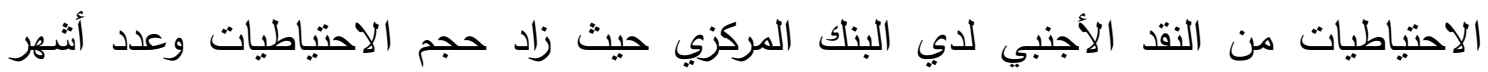

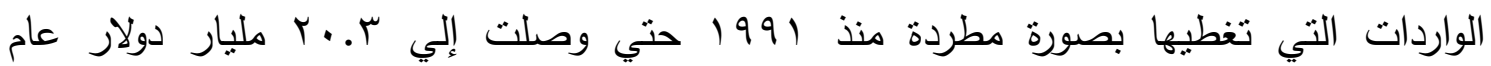

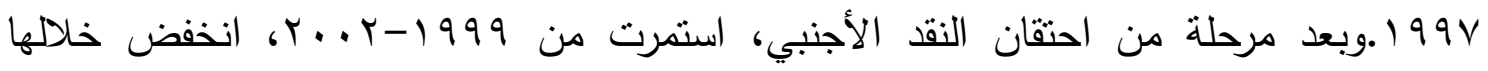


مستوي الاحتباطيات، بدأت مرحلة جديدة من الزيادة ابتداءً من r. r. بمفعول تدفق الاستثمار

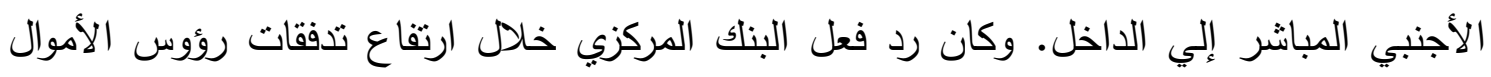

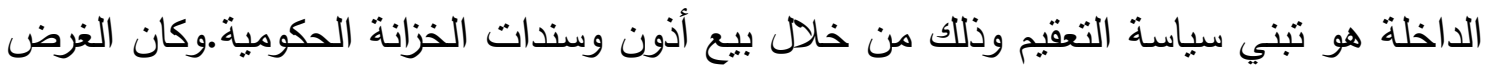

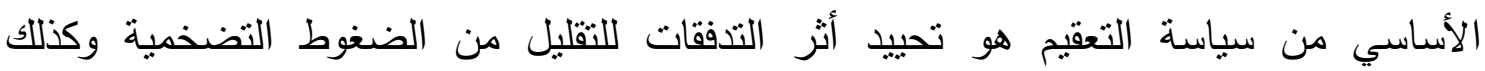
الدحافظة علي سعر الصرف الاسمي المربوط. وقد أدت سياسة التعقيم إلي ارتفاع أسعار الفائدة مما أدي إلي جذب مزيد من تدفقات رؤوس الأموال قصيرة الأجل.

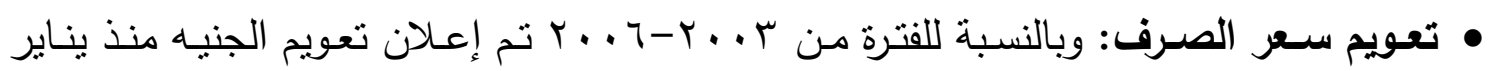

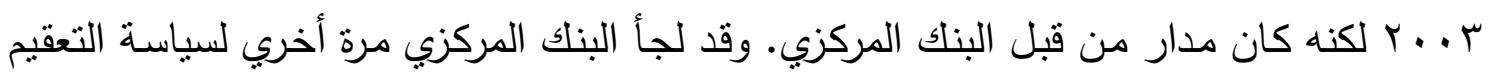

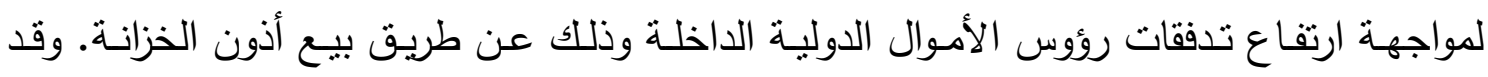

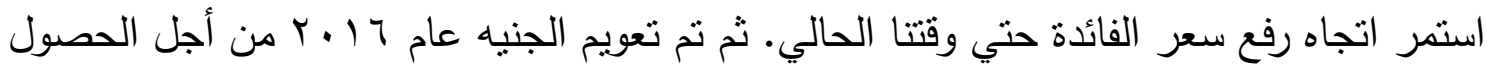

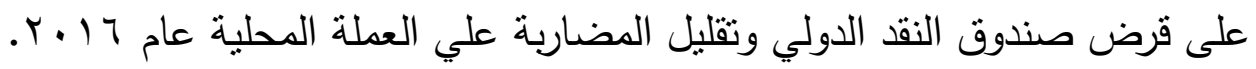

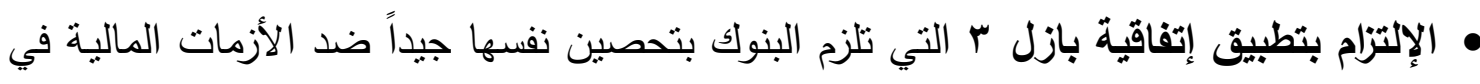

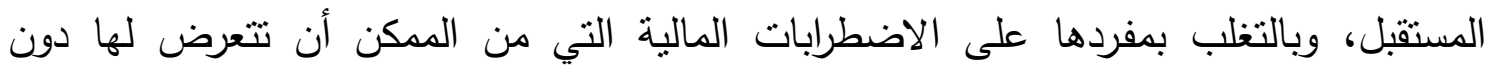

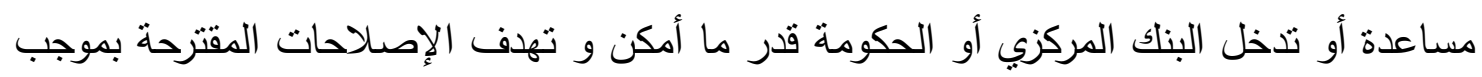

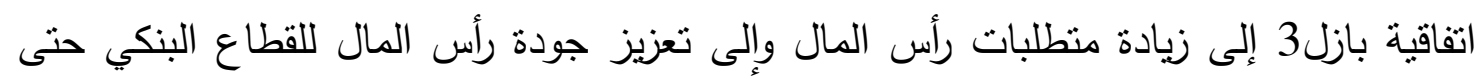

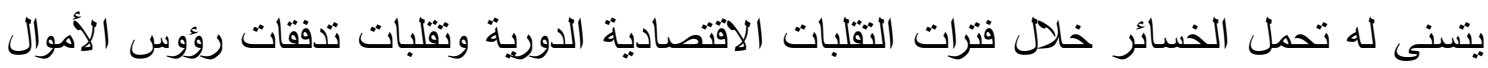

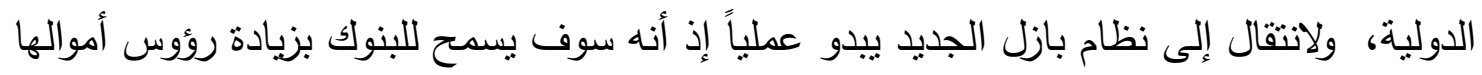

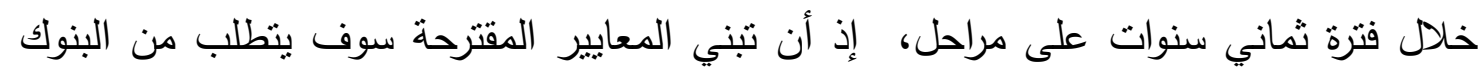

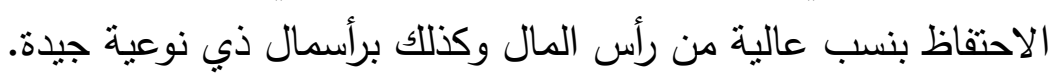

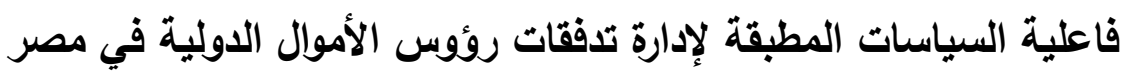


لم تنجح سياسات إدارة تدفقات رؤوس الأموال الواردة (السابقة) في تقليل المخاطر المرتبطة بتلك التدفقات حيث زاد عدم استقرار سعر الصرف في مقابل الدولار وزادت أنشطة المضاربة نتيجة زيادة تدفقات رؤوس الأموال الساخنة مقارنة بالاستثمارات طويلة الأجل.أيضاً نلاحظ تراكم الدين العام نتيجة اتباع سياسة التعقيم بشكل مستمر مما يؤدي إلي تكبد البنك المركزي تكاليف عالية (قدرتها بعض الدراسات حوالي ( \% من الناتج المحلي الإجمالي). أيضاً أدت الإدارة الحالية لتدفقات رؤوس الأموال الدولية إلي زيادة الدين الخارجي وخاصة الديون قصيرة الأجل. وبالتالي لابد من إعادة النظر في تلك السياسات، مراعاة زيادة التمويل من خلال أسهم الملكية مقابل التمويل من خلال الدين Equity versus debt لأنه ينقل المخاطر إلي الدولة المصدرة لرؤوس الأموال بعيداً عن مستخدم تلك الأموال. ينبغي أن تستخدم تدفقات العملة الأجنبية

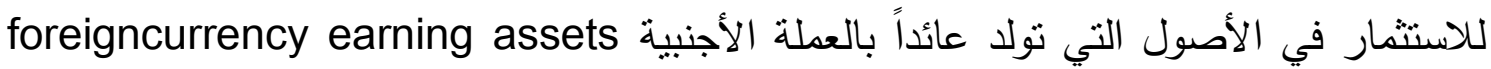
يتم توجيه الاقتراض بالعملة الأجنبية (قرض صندوق النقد الدولي) لتمويل الاستثمارات الموجهة

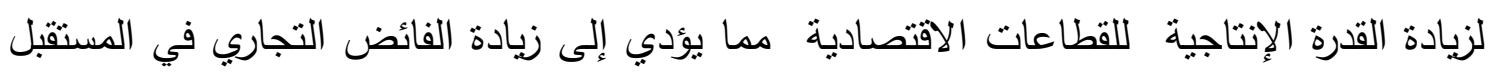

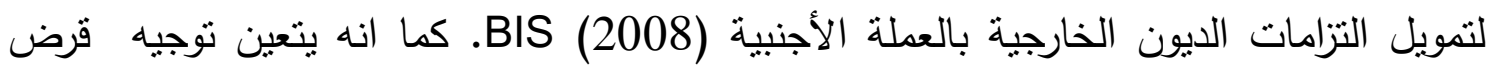
صندوق النقد الدولي للاستثمار بدلاً من الاستهلاك حيث يؤدي توجيه تدفقات رؤوس الأموال لتمويل إنفاق القطاع الحكومي إلي عدم القدرة علي تحقيق الاستدامة المالية. وأخيراً يمكن تطبيق الضوابط علي رؤوس الأموال الدولية الواردة بشكل بسمح بتغير هيكل تدفقات رؤوس الأموال وفترات استحقاقها وأن تكون أكثر انتقائية فيما يتعلق بنوع الاستثمار الذي تحتاجه الدولة والقطاعات المستهدف تطويرها. ويالنسبة لإدارة تدفقات رؤوس الأموال الخارجة Capital outflows، ققد شهدت مصر خروجاً

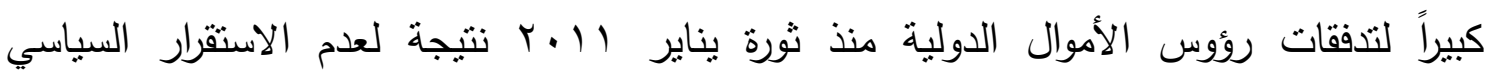

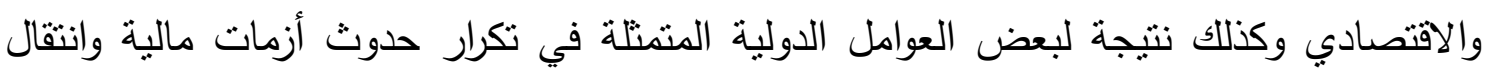

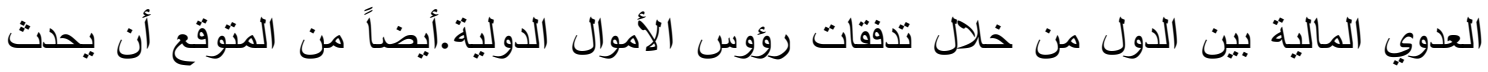


خروج لتدفقات رؤوس الأموال الدولية من مصر مع الإلغاء التدريجي لسياسات التيسير الكمية المتبعة في الولايات المتحدة.

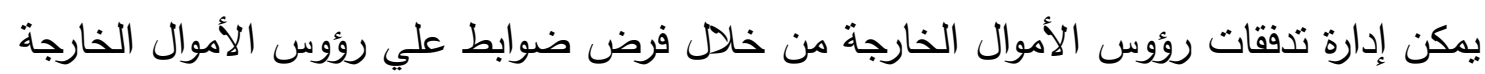

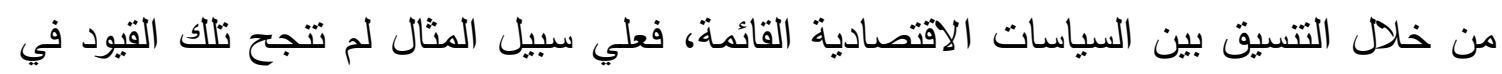

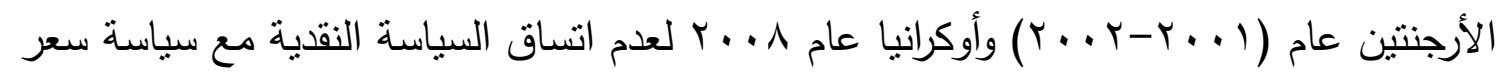

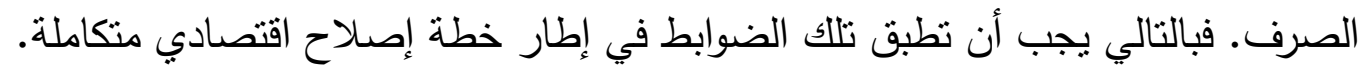

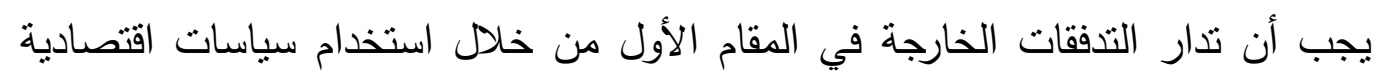

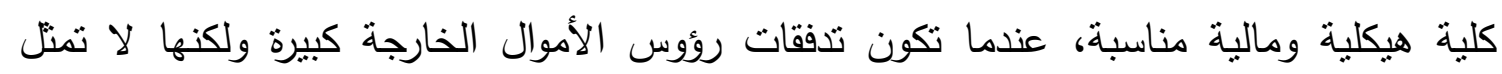

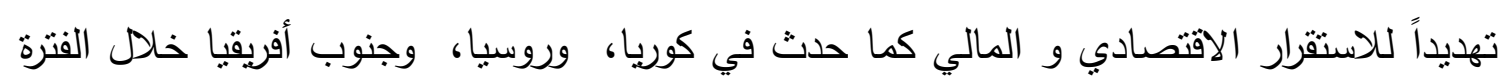

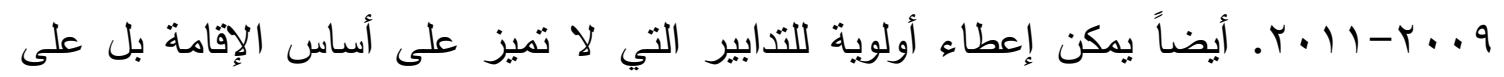

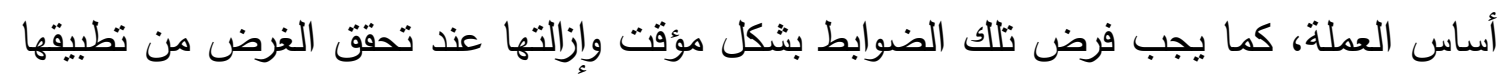
.IMF (2012)

هناك بعض الأمثلة للتدابير التي يقترح تطبيقها في الفترة الحالية للتقليل من خروج رؤوس الأموال

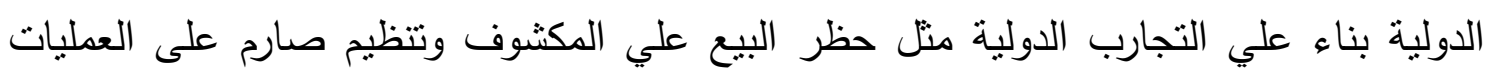

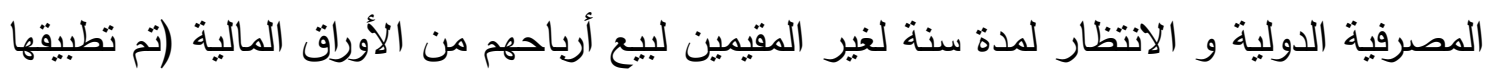

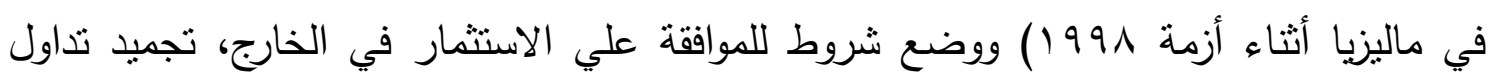

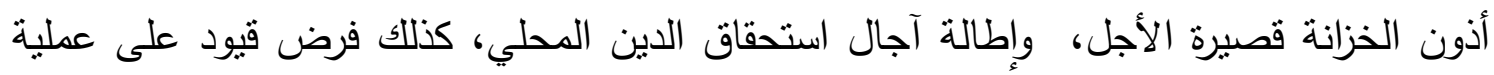

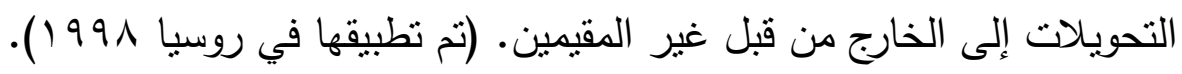

' تعتبر سياسة التيسير الكمبة أحد أدوات السياسة النقدية غير التقليدية حيث يقوم البنك بشر اء

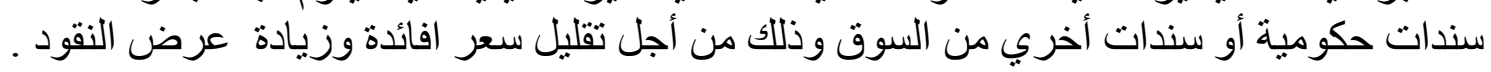


اليمكن الرجوع إلي بنك التسويات الدولية للمزيد عن مفهوم السيولة الدولية ومؤشر اتها عبر الموقع

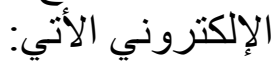
http://www.bis.org/statistics/gli.htm

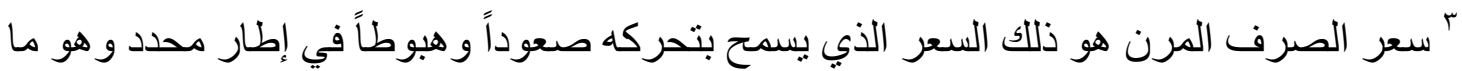

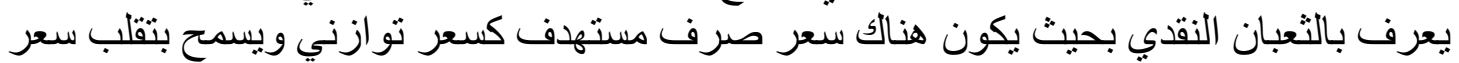

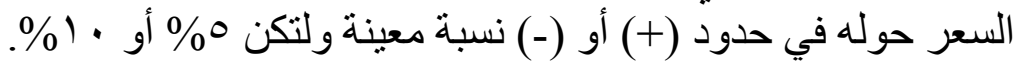
قائمة المراجع

• النشار، ساره، 9 . . r، الدين العام والإدارة الاقتصادية الكلية في مصر (مع التركيز علي أثز

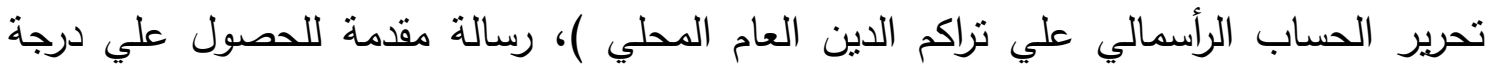
الماجيستير في الاقتصاد، جامعة القاهرة ، كلية الاقتصاد والعلوم السياسية، قسم الاقتصاد.

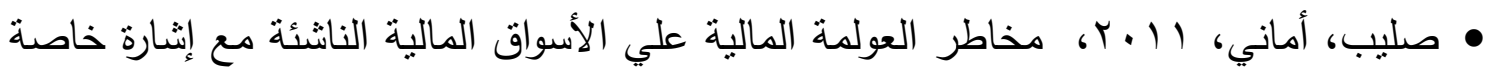

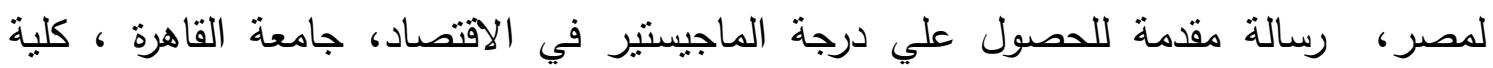
الاقتصاد والعلوم السياسية، قسم الاقتصاد

- Tresor-Economics ,july 2010,which emerging countries have experienced sudden stop of capital inflows during the recent crisis, No.76.

- Garcia, Clara, 2004, Capital inflows, policy responses, and their ill consequences : Thailand, Malaysia, and Indonesia in the decade before the crises, Political economy research institute, working paper series no.81.

- Hwee,Chow,2008, Managing Capital Flows: The Case of Singapore, ADB Institute Discussion Paper No. 86

- Kim, Soyoung \& Yang, Doo, 2008, Managing Capital Flows:The Case of the Republic of Korea, ADB Institute Discussion Paper No. 88.

- Cuadra,et al.,(2010), Global liquidity, capital flows and challenges for policymakers: the Mexican experience,BIS paper No.57. 
- Jara, Alejandro,2013, The Chilean experience managing capital inflows,Policy Workshop on: "International Capital Flows and Financialisation of the South African Economy: Policy Options for Stimulating Employment-driven New Growth Path" Pretoria, 3-4 October 2013.

- European Central Bank, Sept 2016, Dealing with large and Volatile capital flows and the Role of the IMF, IRC Task force on IMF Issues

- Fratzscher, Marcel,2011, Push factors versus pull factors as drivers of global capital flows,CEPR's policy portal .

- Johnston ,R. \& Inci Robe ,1999, Modernized approach to managing the risks in cross border capital movement, IMF policy discussion paper $\mathrm{pdp} / 99 / 6$

- Bank of international settlement, Dec 2008, Financial globalization and emerging market capital flows, BIS Papers No 44.

- Ariyoshi, Akira, Karl Habermeier, Bernard Laurens, Inci Otker-Robe, Jorge Ivan Canales-Kriljenko and Andrei Kirilenko. 2000. "Capital

Controls: Country Experiences withTheir Use and Liberalization," IMF Occasional Paper 190, (Washington DC).

- Levine, Ross, (2006) A New Database on Financial Development and Structure, available at http://go.worldbank.org/X23UD9QUX0.

- Yap, Josef T. 2008. Managing Capital Flows: The Case of the Philippines. ADBI Discussion Paper 91. Tokyo: Asian Development Bank Institute.

- Yu, Yongding. 2008. Managing Capital Flows: The Case of the People's Republic of China.ADBI Discussion Paper 96. Tokyo: Asian Development Bank Institute. 


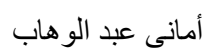

المجلة المصرية للنتمية والتخطيط

- García , Clara , Capital inflows, policy responses, and their ill effects:

Thailand, Malaysia, and Indonesia in the decade before the crises, Universidad Complutense de Madrid

- http://pendientedemigracion.ucm.es/info/epm/miembro s/garcia2007.pdf.

- Cordero, JoséAntonio \& Juan Antonio, 2010, Capital Controls and Monetary Policy in Developing Countries, center for economic policy and research, Washington, D.C.

- Kregel, Jan,April 2009, Managing the Impact of Volatility in International Capital Markets in an Uncertain World, The Levy Economics Institute, Working Paper No. 558.

- IMF, Fiscal rules dataset:

http://www.imf.org/external/datamapper/FiscalRules/map/map.htm

- Takagi, Shinji \&Masahiro Kawai, March 2008, A Survey of the Literature on Managing Capital ,ADB Institute, Discussion Paper No. 100

- Claessens, Stijn, Swatish R. Ghosh, Roxana Mihet, 2013, MacroPrudential Policies to Mitigate Financial System Vulnerabilities," Journal of International Money and Finance 39

- Acharya, Viral, 2013,“Adapting Micro -prudential Regulation for Emerging Markets", Report commissioned by the World Bank's Poverty Reduction and Economic Management (PREM) Network, May (Washington: The World Bank). In Otaviano Canuto and Swati R. Ghosh (eds.), Dealing with the Challenges of Macro Financial Linkages in Emerging Markets, World Bank, Washington, D.C. pp. 57

- IMF, 2012, Liberalizing Capital Flows and Managing Outflows, Prepared by the Monetary and Capital Markets Department; the Strategy, Policy, and Review Department; and the Research Department, in consultation with the Legal Department 
$1 \ldots$ 